\title{
Evidence of improvement in thermoelectric parameters of n-type Bi2Te3/graphite nanocomposite
}

Article

Accepted Version

Singha, P., Das, S., Kulbachinskii, V. A., Kytin, V. G., Apreleva, A.S., Voneshen, D. J., Guidi, T., Powell, A. V., Chatterjee, S., Deb, A. K., Bandyopadhyay, S. and Benerjee, A. (2021)

Evidence of improvement in thermoelectric parameters of $n$ type Bi2Te3/graphite nanocomposite. Journal of Applied Physics, 129 (5). 055108. ISSN 0021-8979 doi: https://doi.org/10.1063/5.0030745 Available at https://centaur.reading.ac.uk/96632/

It is advisable to refer to the publisher's version if you intend to cite from the work. See Guidance on citing.

To link to this article DOI: http://dx.doi.org/10.1063/5.0030745

Publisher: American Institue of Physics

All outputs in CentAUR are protected by Intellectual Property Rights law, including copyright law. Copyright and IPR is retained by the creators or other copyright holders. Terms and conditions for use of this material are defined in the End User Agreement. 


\section{CentAUR}

Central Archive at the University of Reading

Reading's research outputs online 


\title{
Evidence of improvement in thermoelectric parameters of $\boldsymbol{n}$-type $\mathrm{Bi}_{2} \mathrm{Te}_{3}$ /graphite nanocomposite
}

\author{
P. Singha ${ }^{1}$, Subarna Das ${ }^{1}$, V. A. Kulbachinskii ${ }^{2,3}$, V. G. Kytin ${ }^{2}$, A. S. Apreleva ${ }^{2}$, D. J. Voneshen ${ }^{4,5}$, T. \\ Guidi $^{4}$, Anthony V. Powell ${ }^{6}$, S. Chatterjee ${ }^{7}$, A. K. Deb ${ }^{8}$, S. Bandyopadhyay ${ }^{1,9}$, and Aritra Banerjee ${ }^{1,9, a}$
}

${ }^{1}$ Department of Physics, University of Calcutta, 92 A P C Road, Kolkata, West Bengal 700 009, India

${ }^{2}$ Department of Low temperature Physics and Superconductivity, Physics faculty, M V Lomonosov Moscow State University, 119991 GSP-1, Moscow, Russia

${ }^{3}$ Moscow Institute of Physics and Technology, 141700 Dolgoprudny, Moscow Region, Russia

${ }^{4}$ ISIS Pulsed Neutron and Muon Source, Rutherford Appleton Laboratory, Didcot, OX11 0QX, United Kingdom

${ }^{5}$ Department of Physics, Royal Holloway University of London, Egham, TW20 0EX, United Kingdom

${ }^{6}$ Department of Chemistry, University of Reading, RG6 6AD Reading, United Kingdom

${ }^{7}$ UGC-DAE Consortium for Scientific Research, Kolkata Centre, Sector III, LB-8, Salt Lake, Kolkata 700 106, India

${ }^{8}$ Department of Physics, Raiganj University, Uttar Dinajpur, West Bengal 733 134, India

${ }^{9}$ Center for Research in Nanoscience and Nanotechnology, University of Calcutta, JD-2, Sector-III, Salt Lake, Kolkata, West Bengal 700 106, India

\footnotetext{
a)Author to whom correspondence should be addressed. Electronic mail: arbphy@caluniv.ac.in
} 


\begin{abstract}
Improvement of thermoelectric parameters is reported with graphite incorporation in n-type $\mathrm{Bi}_{2} \mathrm{Te}_{3} /$ graphite nanocomposite system. In-depth thermoelectric properties of nanostructured $\mathrm{Bi}_{2} \mathrm{Te}_{3} /$ graphite composites are probed both microscopically and macroscopically using X-ray diffraction, Raman spectroscopy, inelastic neutron scattering and measurement of the temperature dependence of thermal conductivity $\kappa$, Seebeck coefficient $S$, resistivity $\rho$, and carrier concentration $n_{H}$. Raman spectroscopic analysis confirms that graphite introduces defects and disorder in the system. Graphite addition induces a large (17\%) decrease of $\kappa$, originating from a strong phonon scattering effect. A low lattice thermal conductivities $\kappa L$, value of $0.77 \mathrm{Wm}^{-1} \mathrm{~K}^{-1}$, approaching the $\kappa_{\min }$ value, estimated using the Cahill-Pohl model, is reported for $\mathrm{Bi}_{2} \mathrm{Te}_{3}+1 \mathrm{wt} \%$ graphite sample. Graphite dispersion alters the low energy inelastic neutron scattering spectrum providing evidence for modification of the $\mathrm{Bi}_{2} \mathrm{Te}_{3}$ Phonon Density of States (PDOS). Improvement of the other thermoelectric parameters, viz., Seebeck Coefficient and resistivity, is also reported. Theoretical modeling of electrical and thermal transport parameters is carried out and a plausible explanation of the underlying transport mechanism is provided assuming a simple model of ballistic electron transport in 1D contact channels with two different energies.
\end{abstract}




\section{INTRODUCTION}

Thermoelectric (TE) devices enable direct conversion between thermal and electrical energy and are considered as an alternative source for power generation and refrigeration. ${ }^{1,2}$ The attractive features such as an environmentally-friendly technology, zero-emission advantage, no moving parts, high reliability, and low maintenance cost have renewed research activity in the field of TE materials worldwide. ${ }^{3}$ Recent TE research has focused on nanoscale modifications of potential TE materials ${ }^{4}$, and the application of a variety of approaches to improving the performance of existing materials. ${ }^{5-7}$ The performance of a TE material is quantified by the dimensionless parameter, TE figure of merit, $Z T=\frac{S^{2}}{\rho \kappa} T$, where $S, \rho, \kappa$ are the Seebeck coefficient (thermopower), electrical resistivity, and thermal conductivity of the material respectively and $\mathrm{T}$ is the absolute temperature. It should be acknowledged that phonons, charge carriers, magnetons, excitons, and photons can all, in principle, contribute to the transport of heat, but the principal contributions to $\kappa$ in thermoelectrics are from phonons $\left(\kappa_{L}\right)$ and charge carriers $\left(\kappa_{e}\right)$, i.e., $\kappa=\kappa_{L}+\kappa_{e}$. A high TE $Z T$ is obtained with large $S$ but low $\rho$ and $\kappa$. This is almost impossible to achieve simultaneously since the material parameters are interrelated and depend on carrier concentration, electronic structure, and microstructure of the TE material. Thus, to enhance $Z T$, it is necessary to try to decouple these parameters, which are inherent to a material. ${ }^{1-3,8,9}$

The concept of quantum confinement for decoupling these three parameters was proposed by Hicks et al. ${ }^{10}$ Introduction of a low-dimensional nanoscale phase into the TE matrix generates additional interfaces, which scatter phonons more effectively than electrons. ${ }^{2}$ In recent years, significant effort has been directed to decoupling these parameters in order to enhance the power factor $\left(\mathrm{PF}=S^{2} / \rho\right)$ and decrease $\kappa$, and hence improve $Z T \cdot{ }^{6-12}$ The increased phonon scattering at the newly formed interfaces between the matrix and dispersoids, results in a lowering of $\kappa_{L} .^{5,7,12-16}$ Furthermore, the additional interfaces in nanocomposites act as an energy barrier. By suppressing the 
transport of mid and long-wavelength phonons, which carry a considerable fraction of the heat, nanometer-sized grain boundaries can reduce the phonon contribution $\left(\kappa_{L}\right)$ to thermal conduction, leading to a substantial increase in $Z T .{ }^{17}$ The incorporation of carbon allotropes, such as Carbon Nanotubes $(\mathrm{CNT})^{12}$ or $\mathrm{C}_{60}{ }^{13}$ has been beneficial to increase $Z T$ in $\mathrm{Bi}_{2} \mathrm{Te}_{3}$ based materials.

$\mathrm{Bi}_{2} \mathrm{Te}_{3}$, a narrow band gap $\left(\mathrm{E}_{\mathrm{g}} \sim 0.20 \mathrm{eV}\right)$ semiconductor, is the state-of-the-art TE material close to room temperature. ${ }^{1,2,8,14,18}$ It adopts a layered structure described in the space group $R \overline{3} m-D_{3 d}^{5} \cdot{ }^{1,2,6,18}$ It is also a well-known topological insulator ${ }^{19}$ and extensively used in areas such as medical appliances and microelectronic devices. ${ }^{20}$ Interestingly $\mathrm{Bi}_{2} \mathrm{Te}_{3}$ can be synthesized in both $n$ type and $p$-type forms and hence plays an important role in the design of TE devices. ${ }^{1,3,18}$ Improving the performance of $\mathrm{Bi}_{2} \mathrm{Te}_{3}$ based materials has been a major thrust of $\mathrm{TE}$ research over the past decades. ${ }^{2,12,14}$

Graphite also adopts a layered structure, consisting of a succession of covalently-bonded layers of carbon atoms stacked in a direction perpendicular to the basal plane. There are weak interactions of the van der Waals' type between individual carbon layers, giving the structure a high degree of anisotropy, which manifests itself in the physical properties. ${ }^{21,22}$ For example, phonons propagate quickly along the tightly-bound planes, but are slower to travel from one plane to another, resulting in the in-plane thermal conductivity being significantly higher than that in the out of plane direction. As a functional and ecofriendly material, graphite has high electrical in-plane conductivity and excellent mechanical properties and low cost. ${ }^{22}$ These factors encourage us to choose graphite as a possible dispersed phase in the $\mathrm{Bi}_{2} \mathrm{Te}_{3}$ matrix.

In the present study, we have synthesized n-type $\mathrm{Bi}_{2} \mathrm{Te}_{3}+\mathrm{x}$ wt $\%$ graphite $(\mathrm{x}=0,0.5$, and 1.0) composites. The detailed structural and microstructural analysis, Raman spectroscopic measurements along with temperature dependent TE parameters viz., thermopower, $S(\mathrm{~T})$; electrical resistivity, $\rho(\mathrm{T})$; Hall concentration, $n_{H}(\mathrm{~T})$; thermal conductivity, $\kappa(\mathrm{T})$; and lattice thermal conductivity, $\kappa_{L}$ of the synthesized nanostructured $\mathrm{Bi}_{2} \mathrm{Te}_{3} /$ graphite composites are reported. A large 
reduction in $\kappa_{L}$ is observed with the addition of graphite. The influence of graphite on the low energy phonon density of states (PDOS) has been experimentally verified with inelastic neutron scattering (INS). Our experimental results reveal a simultaneous improvement of electrical conductivity, $\sigma$ and Seebeck coefficient, $S$ together with a decrease in $\kappa$. Here, it should be emphasized that the measurements have been conducted on materials for which there had been no attempt to optimize the charge carrier concentration $\left(n_{H}\right)$ as the focus of the work was to explore the impact of the introduction of graphite on the thermal transport properties. Consequently, the figure of merit remains below that of state of the art materials. The incorporation of graphite allows tailoring of TE properties of $\mathrm{Bi}_{2} \mathrm{Te}_{3}$ nanocomposites. Furthermore, the experimental data are theoretically simulated and reasonable quantitative agreement with experimental data is obtained considering the nanostructured composites as a network of resistors representing 1D contact channels, with ballistic electron transport within two groups of 1D channels having different energies. The underlying physics with an insight towards modification of the desired property for obtaining better TE materials are discussed.

\section{EXPERIMENTAL METHODS}

$\mathrm{Bi}_{2} \mathrm{Te}_{3}+\mathrm{x}$ wt $\%$ graphite $(\mathrm{x}=0,0.5$, and 1.0$)$ nanocomposites were synthesized by mixing different weight percentages of graphite with $\mathrm{Bi}_{2} \mathrm{Te}_{3}$ ingots. Polycrystalline $\mathrm{Bi}_{2} \mathrm{Te}_{3}$ ingots were synthesized by a solid-state reaction method. Stoichiometric amounts of bismuth and tellurium (each of purity 99.999\%; Alfa Aesar, UK) were vacuum-sealed in evacuated ( 10 $\left.0^{-3} \mathrm{mbar}\right)$ quartz tubes to avoid oxidation. Vacuum sealed quartz ampoules were annealed at $1083 \mathrm{~K}$ for $24 \mathrm{~h}$ and then cooled to $863 \mathrm{~K}$ at a rate of $5 \mathrm{~K} /$ hour. To homogenize the mixture, it was sintered at $863 \mathrm{~K}$ for 96 hours, followed by quenching in liquid nitrogen. The $\mathrm{Bi}_{2} \mathrm{Te}_{3}$ ingots thus obtained were first ground, subsequently mixed with the desired weight percentage of graphite and then ball milled for $10 \mathrm{~h}$, in an argon atmosphere to avoid oxidation, using a planetary ball mill [Model: Pulverisette (Fritsch, 
Germany)]. High purity natural graphite powder (purity 99.9995\%; -325 mesh; Alfa Aesar, UK) was used. For ball milling, an agate container and balls were employed. The ball to sample mass ratio was $\sim 10: 1$, and the speed of the main disk was maintained at $200 \mathrm{rpm}$. For measurement of TE parameters, the nanocomposite powders were then hot-pressed in vacuum into pellets of diameter 10 $\mathrm{mm}$ and thickness about $2 \mathrm{~mm}$. The hot pressing was done at $698 \mathrm{~K}$ for 1 hour under a pressure of 70 $\mathrm{MPa}$ in a graphite die. The density of all the hot-pressed samples is of the same order $(\sim 82 \%$ of the theoretical density). It should be pointed out that such procedure of synthesis gives n-type $\mathrm{Bi}_{2} \mathrm{Te}_{3} /$ graphite nanocomposite samples. The structural analysis of the synthesized samples was carried out using powder X-ray diffraction (Model: X'Pert Powder, PANalytical, The Netherlands) with $\mathrm{Cu}-\mathrm{K}_{\alpha 1}$ radiation of wavelength $0.154056 \mathrm{~nm}$. All X-ray diffraction (XRD) measurements were performed at room temperature on powdered samples in the angular range $5 \leq 2 \theta /{ }^{\circ} \leq 120$ in $\theta-2 \theta$ geometry. Data were analysed by the Rietveld refinement technique, utilizing the Materials Analysis Using Diffraction (MAUD) program. ${ }^{23}$ A silicon standard was used to determine the instrumental profile. $^{24}$ Room temperature Raman spectroscopic studies (Model: inVia, Renishaw, UK) were performed in the range $50-3000 \mathrm{~cm}^{-1}$ with a $514.5 \mathrm{~nm} \mathrm{Ar}^{+}$laser. Submicron focusing diameter (objective of 50X magnification with numerical aperture 0.8) was used. For monochromatization, $1800 \mathrm{gr} / \mathrm{mm}$ grating was used with a Peltier-cooled charged-coupled-device (CCD) detector in the back-scattering configuration. Microstructural analysis of the nanocomoposite samples was carried out using a Transmission Electron Microscope (TEM; JEM 2100 HR, JEOL) operating at $200 \mathrm{KV}$. Temperature dependent resistivity, $\rho(\mathrm{T})$ measurements were carried out in the temperature range of $10 \leq \mathrm{T} / \mathrm{K} \leq 300$ using a standard four-probe technique using silver paste, cured at room temperature for the electrical contacts. The temperature dependence of thermopower, $S(\mathrm{~T})$ in the temperature range $20 \leq \mathrm{T} / \mathrm{K} \leq 300$ was measured using a standard differential technique. ${ }^{25,26}$ The $\rho(\mathrm{T})$ and $S(\mathrm{~T})$ measurements were carried out on parallelepiped shaped samples of dimensions around $6 \times 4 \times 0.8$ $\mathrm{mm}^{3}$ using indigenously built set up; experimental details of which are provided elsewhere. ${ }^{25}$ The 
temperature dependent Hall concentration, $n_{H}(\mathrm{~T})$ measurements were performed by the van der Pauw method in the $10 \leq \mathrm{T} / \mathrm{K} \leq 300$ range on similar bar-shaped samples in a closed cycle refrigerator (CCR) based $12 \mathrm{~T}$ magnet supplied by Cryogenic Ltd., UK. ${ }^{26}$ The thermal conductivity, $\kappa(\mathrm{T})$ of the sample was measured in the temperature range $80 \leq \mathrm{T} / \mathrm{K} \leq 300$, measurement details have been reported earlier. ${ }^{27} \kappa(\mathrm{T})$ was measured in comparison with a reference sample of known $\kappa$ connected in series with the experimented sample. Both the sample and reference were kept inside the thermal screen. ${ }^{27}$ Inelastic neutron scattering (INS) measurements were made using the MARI chopper spectrometer at the ISIS Pulsed Neutron and Muon Source. The obtained data have been divided through Vanadium measured with a white beam to correct for finite detector efficiencies. No multiphonon corrections have been applied. Powdered samples of pristine $\mathrm{Bi}_{2} \mathrm{Te}_{3}$, graphite, and the $\mathrm{Bi}_{2} \mathrm{Te}_{3}$ $+1.0 \mathrm{wt} \%$ nanocomposite were loaded into aluminium-foil sachets. These were mounted in a thinwalled aluminium can, located inside a closed-cycle refrigerator containing He-exchange gas. Measurements of the powdered samples were conducted at $5 \mathrm{~K}$ using incident energies of $\mathrm{E}_{\mathrm{i}}=14,40$ and $140 \mathrm{meV}$. Data manipulation and reduction, including subtraction of the background determined by measuring the empty container, was performed using Mantid..$^{28}$

\section{RESULTS AND DISCUSSION}

\section{Structural properties}

Powder X-ray diffraction patterns of the $\mathrm{Bi}_{2} \mathrm{Te}_{3}+\mathrm{x}$ wt $\%$ graphite $(\mathrm{x}=0,0.5$, and 1.0) samples, presented in the Supplementary Material, can be indexed on the basis of pure $\mathrm{Bi}_{2} \mathrm{Te}_{3}$ (JCPDS card no 15-0863). There is no evidence of impurity peaks or additional peaks due to graphite in the $\mathrm{Bi}_{2} \mathrm{Te}_{3} /$ graphite nanocomposite samples. The amount of graphite is quite small and is probably beyond the detection limit of XRD. Furthermore, the XRD pattern confirms the insolubility of graphite in $\mathrm{Bi}_{2} \mathrm{Te}_{3}$, as no peak shift is observed in the XRD pattern on addition of graphite. The XRD 
patterns after Rietveld refinement are included in the supplementary material. The refinement was carried out using the atomic positions of the pristine $\mathrm{Bi}_{2} \mathrm{Te}_{3}$ samples. The space group $\mathrm{R} \overline{3} \mathrm{~m}$ was used for refinement. The extracted unit cell parameters, the corresponding goodness of fit $(\mathrm{GoF})$ or $\chi^{2}$ values and refinement parameters including site occupancy, atomic positions, reliability parameters $\left(\mathrm{R}_{\mathrm{w}}, \mathrm{R}_{\mathrm{b}}, \mathrm{R}_{\exp }\right)$ along with other important parameters are provided in the supplementary material. No significant change in lattice parameters with graphite addition is observed. According to the formalism of Popa ${ }^{29}$ the microstructural refinement using MAUD software is capable of modeling both isotropic and anisotropic size and strain broadening. The Williamson-Hall (W-H) analysis indicates that the microstructure of $\mathrm{Bi}_{2} \mathrm{Te}_{3} /$ graphite nanocomposites is anisotropic. Hence, in the present study, Popa's model is incorporated in the Rietveld refinement code
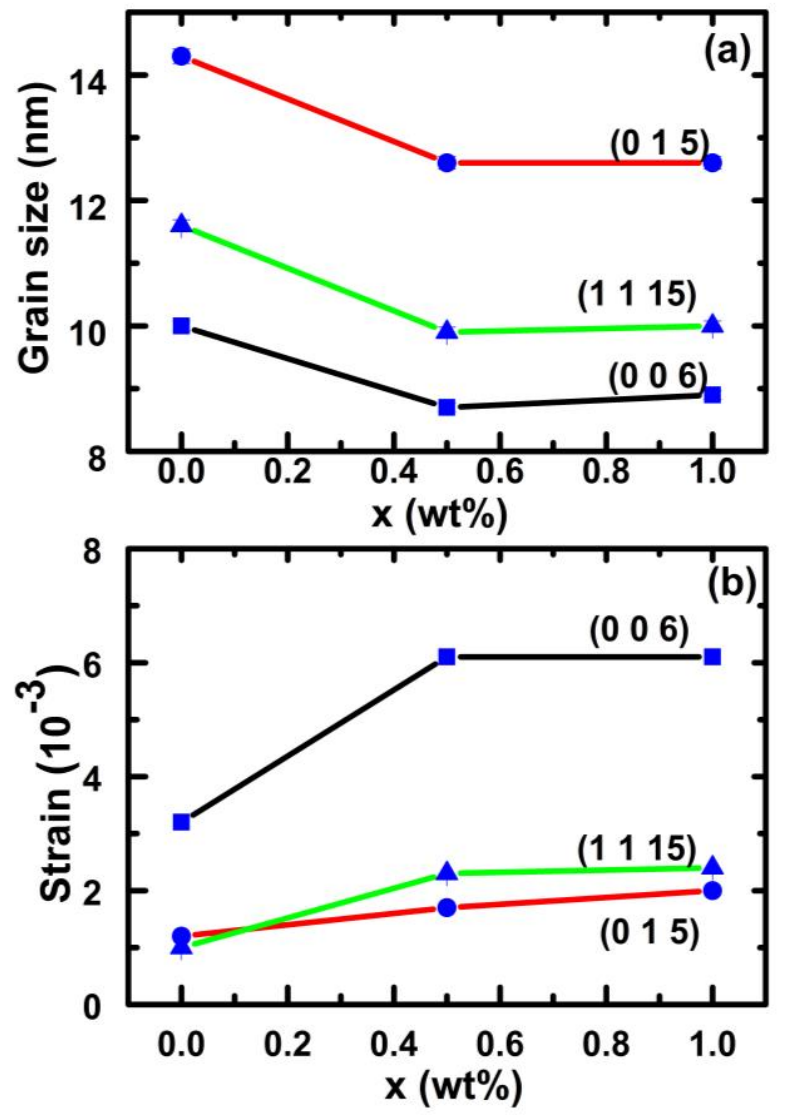

FIG. 1. (a) Grain size and (b) strain of $\mathrm{Bi}_{2} \mathrm{Te}_{3}$ $+\mathrm{x}$ wt $\%$ graphite $(\mathrm{x}=0,0.5$, and 1.0$)$ composites for three typical lattice planes after Rietveld refinement at room temperature. Estimated errors in the grain size and lattice strain are included. Errors in lattice strain ( $1 \%$ ) are within the size of data points.

MAUD using an anisotropic distribution of grain size and strain in all synthesized samples. Fig. 1(a) and Fig. 1(b) depicts the variation of grain size and strain of $\mathrm{Bi}_{2} \mathrm{Te}_{3}+\mathrm{x} w t \%$ graphite $(\mathrm{x}=0,0.5$, and 1.0) composites for three typical lattice planes. It should be mentioned here that the corresponding XRD measurements are performed on the as prepared samples. The grain sizes of all the nanocomposite samples, as obtained after refinement, decrease, whereas lattice strain increases with incorporation of graphite in $\mathrm{Bi}_{2} \mathrm{Te}_{3}$. The incorporation of graphite in the $\mathrm{Bi}_{2} \mathrm{Te}_{3}$ matrix inhibits grain 
growth and increases lattice strain. ${ }^{30}$ This further suggests that graphite particles are embedded in the matrix and present as separate phases in the reported composite samples. However, the presence of graphite is directly probed from Raman spectroscopic measurement and electron microscopic (TEM) analysis.

The Raman spectra of the $\mathrm{Bi}_{2} \mathrm{Te}_{3} /$ graphite nanocomposite samples confirm the presence of graphite (Fig. 2). In the low-frequency region $\left(60-150 \mathrm{~cm}^{-1}\right)$, the peaks observed at around $92 \mathrm{~cm}^{-1}$ and $134 \mathrm{~cm}^{-1}$ are attributed to Raman active $\mathrm{E}_{\mathrm{g}}^{2}$ and $\mathrm{A}_{1 \mathrm{~g}}^{2}$ vibrational modes of $\mathrm{Bi}_{2} \mathrm{Te}_{3}$, respectively. ${ }^{31}$ But in addition to these Raman active vibrational modes, another distinct peak is observed at around $112 \mathrm{~cm}^{-1}$, which probably arises from the infrared (IR) active $\mathrm{A}_{1 \mathrm{u}}$ mode of $\mathrm{Bi}_{2} \mathrm{Te}_{3}{ }^{31,32}$ Generally, IR active phonon modes of oddparity are not observed in the Raman spectra of centrosymmetric crystals. The observation of the infrared active Alu phonon mode (Fig. 2) may be due to strong confinement effects and the loss of local inversion symmetry, as has previously been observed in nanostructured samples. ${ }^{32}$ The presence of a similar IR active phonon mode in Raman spectra has been reported earlier by Shahil et al. in mechanically exfoliated few-quintuple layers of $\mathrm{Bi}_{2} \mathrm{Te}_{3} .{ }^{32} \mathrm{In}$

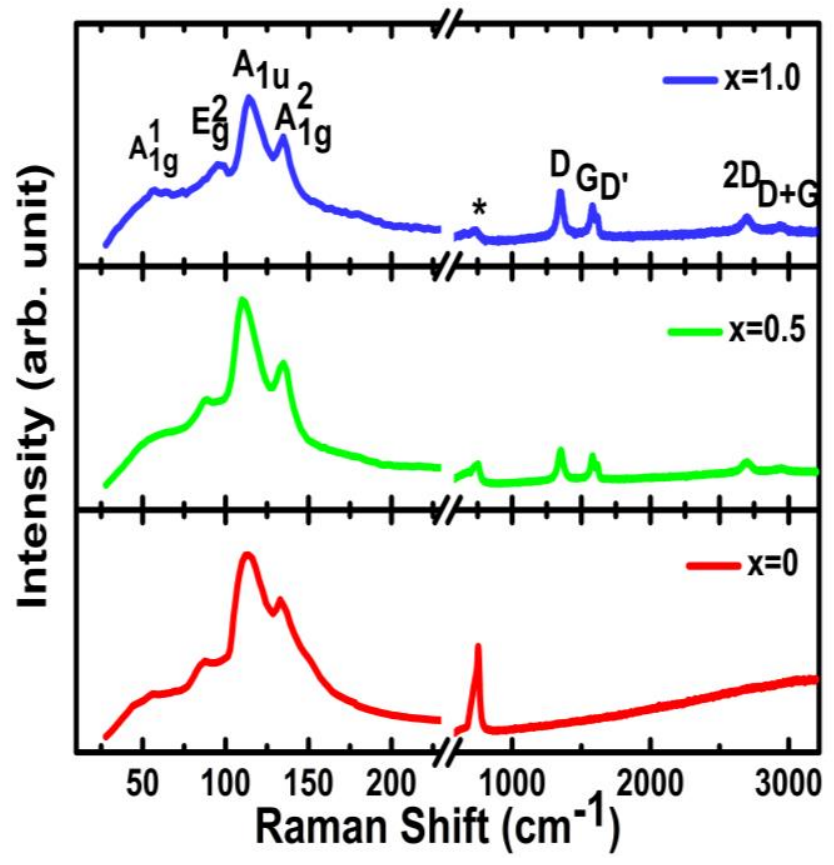

FIG. 2. Room temperature Raman spectra of $\mathrm{Bi}_{2} \mathrm{Te}_{3}+\mathrm{x}$ wt $\%$ graphite $(\mathrm{x}=0,0.5$, and 1.0) nanocomposites. The peak marked with asterisk (*) $^{*}$ is attributed to the overtone modes of nanostructured $\mathrm{Bi}_{2} \mathrm{Te}_{3}$. addition, a sharp peak around $755 \mathrm{~cm}^{-1}$ is also observed in Fig. 2, which is not a regular Ramanactive mode of $\mathrm{Bi}_{2} \mathrm{Te}_{3}$. In nanostructured composites, different types of defects are induced in the system. The peak around $755 \mathrm{~cm}^{-1}$ can be attributed to the overtone modes arising due to defectinduced crystal symmetry breaking. ${ }^{33}$ 
In addition to the Raman-active peaks observed in pristine $\mathrm{Bi}_{2} \mathrm{Te}_{3}$, the Raman spectra of asprepared $\mathrm{Bi}_{2} \mathrm{Te}_{3} /$ graphite composite samples exhibit several Raman-active bands due to graphite. The peak at $1580 \mathrm{~cm}^{-1}$ is one of the most critical features in the Raman spectra of graphitic materials and is ascribed to the $\mathrm{G}$ band $\left(1580 \mathrm{~cm}^{-1}\right)$ arising from the vibration of $\mathrm{sp}^{2}$-hybridized carbon. ${ }^{34}$ Furthermore, peaks due to the D band $\left(1350 \mathrm{~cm}^{-1}\right), \mathrm{D}^{\prime}$ band $\left(1616 \mathrm{~cm}^{-1}\right)$, and $\mathrm{G}^{\prime}$ band $\left(2697 \mathrm{~cm}^{-1}\right)$ of graphite are also observed in the Raman spectra of nanostructured $\mathrm{Bi}_{2} \mathrm{Te}_{3}$ /graphite composite samples. ${ }^{35}$ Generally, for highly crystalline graphite, D and D' bands are absent. The Raman active peak at about $2948 \mathrm{~cm}^{-1}$ in Fig. 2 is associated with a D + G combination mode and is also induced by disorder in the system due to nanostructured graphite. Prominent peaks $\sim 2710 \mathrm{~cm}^{-1}$ and $2941 \mathrm{~cm}^{-}$ ${ }^{1}$ are also observed, corresponding to the double resonant scattering process from the zone-edge phonons of graphite. ${ }^{34,35}$ Nanostructured graphite possesses different kind of defects. Ball milling of low-dimensional graphite may be responsible for the introduction of defects and disorder into the nanocomposite system. Raman spectra, which confirm the absence of reaction between graphite and $\mathrm{Bi}_{2} \mathrm{Te}_{3}$, complement the XRD data and substantiate that graphite is present as a second phase in the matrix of $\mathrm{Bi}_{2} \mathrm{Te}_{3}$.

Direct structural evidence for the presence of graphite in $\mathrm{Bi}_{2} \mathrm{Te}_{3}$ matrix and the nature of its distribution are further confirmed through micro-structural analysis. A high resolution TEM image of $\mathrm{Bi}_{2} \mathrm{Te}_{3}+1 \mathrm{wt} \%$ graphite nanocomposite sample is illustrated in the supplementary material [Fig. SM2]. Micrograph of a typical $\mathrm{Bi}_{2} \mathrm{Te}_{3} /$ graphite composite sample with highest graphite concentration $(\mathrm{x}=1.0)$ is presented. Several lattice stripes with definite widths of $0.322 \mathrm{~nm}, 0.268 \mathrm{~nm}$ and $0.237 \mathrm{~nm}$ clearly represent respectively the (015), (018), and (1010) planes of $\mathrm{Bi}_{2} \mathrm{Te}_{3}$. Some less dark regions (marked by dotted circles) identified as graphite, indicate that graphite is randomly dispersed in the $\mathrm{Bi}_{2} \mathrm{Te}_{3}$ matrix. 


\section{Thermoelectric properties characterization}

The total thermal conductivity $\kappa$, of all the samples is shown in Fig. 3(a). A large, around $17 \%$, decrease in $\kappa$ is obtained with graphite addition. A typical room temperature value of $\kappa \sim 0.97$ $\mathrm{Wm}^{-1} \mathrm{~K}^{-1}$ is observed for pristine $\mathrm{Bi}_{2} \mathrm{Te}_{3}$, which gradually decreases to $\sim 0.81 \mathrm{Wm}^{-1} \mathrm{~K}^{-1}$ with an addition of $1.0 \mathrm{wt} \%$ graphite. Porosity is known to play an important role to reduction in the $\kappa$ of materials. Thus porosity correction of $\kappa(\mathrm{T})$ is provided in the Supplementary Material. It is observed that the $\kappa(\mathrm{T})$ value, as obtained after the porosity correction, follows a similar trend with temperature and graphite variation. The main factor influencing $\kappa$ of the nanocomposite samples is the lattice scattering of phonons..$^{5,18,19}$ Hence, an attempt has been made to extract $\kappa_{L}$ for the synthesized samples [Fig. 3(b)]. $\kappa_{L}$

is obtained by subtracting $\kappa_{e}$ [Fig. 3(c)] from $\kappa . \kappa_{e}(=L \sigma \mathrm{T}$, where $L$ is the Lorentz number) is estimated on the

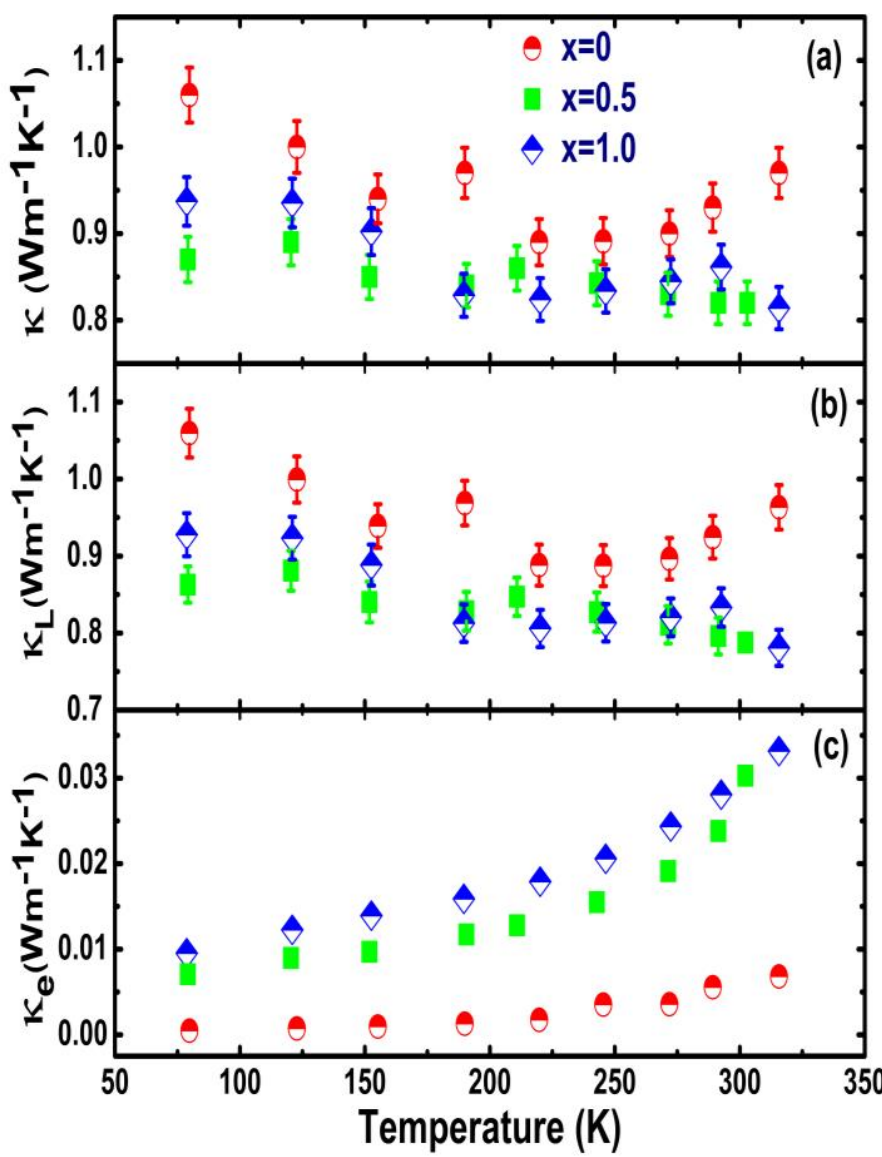

FIG. 3. Temperature dependence of (a) thermal conductivity $(\kappa)$ and (b) lattice part of thermal conductivity $\left(\kappa_{L}\right)$ (c) electronic part of thermal conductivity $\left(\kappa_{e}\right)$ for different weight percentage $(\mathrm{x})$ of graphite in $\mathrm{Bi}_{2} \mathrm{Te}_{3} /$ graphite nanocomposites. The typical errors in $\kappa_{e}$ value are within the size of the data points.

basis of the $L$ value obtained by fitting the Seebeck coefficient data to the reduced chemical potential using a single parabolic band model with acoustic phonon scattering. ${ }^{36}$ In general a simple semiclassical model is not applicable to our samples (see later modeling), but is used here for the purposes of estimation. Fig. 3(b) shows the variation of $\kappa_{L}$ as a function of temperature for $\mathrm{Bi}_{2} \mathrm{Te}_{3}+$ 
x wt $\%$ graphite nanocomposites. Comparing Fig. 3(a) and 3(b) suggest that $\kappa$ is dependent primarily on $\kappa_{L}$ and shows similar temperature and graphite content dependencies. Pristine $\mathrm{Bi}_{2} \mathrm{Te}_{3}$ has the highest $\kappa_{L}$ among all the synthesized samples over the entire temperature range and with addition of graphite $\kappa_{L}$ is effectively reduced in the synthesized nanocomposite samples. A rather low $\kappa_{L}$ of $\sim$ $0.77 \mathrm{Wm}^{-1} \mathrm{~K}^{-1}$ at room temperature is obtained for the $\mathrm{x}=1.0$ sample. Newly formed $\mathrm{Bi}_{2} \mathrm{Te}_{3} /$ graphite heterointerfaces act as effective phonon-scattering centers and lead to the observed decrease of $\kappa_{L}$ in the synthesized nanocomposite samples. It is noteworthy to mention that the $\kappa_{L}$ of all samples shows non-monotonic temperature dependence, viz., decreasing trend with increase of temperature up to $170 \mathrm{~K}$ and then $\kappa_{L}$ increases with further increase in temperature. This may be due to the dominance of phonon scattering in the low temperature regime and above $\sim 170 \mathrm{~K}$, the onset of the bipolar conduction in the material results in the observed temperature dependent behaviour of $\kappa_{L}{ }^{37}$

Similarly low values of $\kappa_{L}$ have been reported in some related TE material, viz., melt spun $\mathrm{Bi}_{2} \mathrm{Te}_{3}$ based compounds, ${ }^{38,39} \mathrm{Bi}_{0.5} \mathrm{Sb}_{1.5} \mathrm{Te}_{3} / \mathrm{C}_{60}$ nanocomposite ${ }^{13}$ and doped $\mathrm{PbTe}^{40}$ Furthermore, the $\kappa_{L}$ value obtained for the present $\mathrm{Bi}_{2} \mathrm{Te}_{3} /$ graphite nanocomposite sample $(\mathrm{x}=1.0)$ approaches the theoretical minimum $\kappa$, $\kappa_{\min }$ of $0.28 \mathrm{Wm}^{-1} \mathrm{~K}^{-1}$ for $\mathrm{Bi}_{2} \mathrm{Te}_{3}$ based materials estimated using the CahillPohl model in the high temperature limit. ${ }^{41,42}$

$$
\kappa_{\min }=\frac{1}{2.48} n^{2 / 3} k_{B}\left(v_{L}+2 v_{T}\right)
$$

Where, $n$ is the number density of the atoms, $k_{B}$ is Boltzmann constant, $v_{L}$ and $v_{T}$ represent longitudinal and transverse sound velocities, respectively. However, it may be necessary to consider higher temperature to confirm the minimum $\kappa_{L}$. Indeed, the phonon-phonon scattering could possibly decrease $\kappa_{L}$ at higher temperature, but in the high temperature limit of Cahill-Pohl model the $\kappa_{\min }$ is already defined by minimal value of the phonon mean free path. For the $\mathrm{Sn}_{1-\mathrm{x}} \mathrm{Sb} b_{\mathrm{x}} \mathrm{Te}$ system, Banik et al. observed the presence of endotaxial nanoscale precipitates of a size similar to that of the mean free path of the heat-carrying phonon in SnTe that effectively scatter phonons and reduce $\kappa_{L} .{ }^{43}$ It 
may, therefore, be assumed that heterointerfaces formed by randomly distributed graphite in $\mathrm{Bi}_{2} \mathrm{Te}_{3}$ nanocomposites effectively scatter heat-carrying phonons of long and mid wavelength, which contributes to the large decrease of $\kappa_{L}$ in $\mathrm{Bi}_{2} \mathrm{Te}_{3}+\mathrm{x}$ wt $\%$ graphite nanocomposites $(\mathrm{x}=0.5$ and 1.0$)$ compared to pristine $\mathrm{Bi}_{2} \mathrm{Te}_{3}(\mathrm{x}=0)$.

In bulk materials, $\kappa_{L}$ is determined by

$$
\kappa_{L}=\frac{1}{3} C_{V} v_{g}^{2} \tau
$$

Where $C_{\mathrm{v}}$ is the specific heat, $v_{\mathrm{g}}$ is the group velocity, and $\tau$ is the phonon relaxation time. In order to achieve a low $\kappa_{L}$, it is desirable to design a TE material with low $C_{v}$, short $\tau$ and slow $v_{g}$. However, the Dulong-Petit limit of high temperature specific heat does not leave much scope for manipulating $C_{v}$ in materials. ${ }^{44}$ Manipulating $\tau$ has been the focus of recent TE materials research. ${ }^{5}$ One common strategy to minimize $\kappa_{L}$ has been to minimize $\tau$ by intensifying the scattering rate of phonons, 5,45 which has been successfully implemented in the $\mathrm{Bi}_{2} \mathrm{Te}_{3} /$ graphite nanocomposite samples reported here. The parameter $\tau$ is frequency-dependent and the scattering probability depends on the concentration of the scattering centers. ${ }^{5}$ 1D dislocations are effective phonon-scattering sources for mid-wavelength phonons. For PbTe thermoelectrics, it has been shown that precipitation of secondary phases of $\mathrm{PbS}$ promotes the formation of dislocations near the boundary due to lattice mismatch between the precipitates and matrix. ${ }^{45}$ Dislocation density $\left(N_{D}\right)$, as estimated from the XRD data, increases with increasing graphite content in the present $\mathrm{Bi}_{2} \mathrm{Te}_{3}$ nanocomposites. The details of the calculation of $N_{D}$ are provided in the supplementary material. The graphite dispersed in the matrix of $\mathrm{Bi}_{2} \mathrm{Te}_{3}$, forms dislocations near the grain boundary and effectively reduces $\kappa_{L}$ due to the scattering of mid wavelength phonons by these boundary dislocations. Furthermore, the increased density of hetero-interfaces formed by graphite randomly distributed in the synthesized $\mathrm{Bi}_{2} \mathrm{Te}_{3}$ composite system also strongly scatter phonons with long-wavelength to reduce $\tau .^{5,40,46}$ In addition, $v_{g}$ also plays an important role in tuning $\kappa_{L}$. Some novel thermoelectrics with intrinsically low $\kappa_{L}$ 
possesses low $v_{\mathrm{g}}$, which can be attributed to weak chemical bonds and/or heavy constituent elements. ${ }^{47}$ In the present $\mathrm{Bi}_{2} \mathrm{Te}_{3}$ nanocomposites, in addition to low $v_{\mathrm{g}}$ arising due to global soft bonds, local soft bonds are simultaneously introduced due to the dispersed second phase of graphite. This local soft bond induces low-frequency optical modes that strongly interact with the highfrequency acoustic modes and leads to further reduction of $v_{\mathrm{g}}$, and hence $\kappa_{L}$. Tian et al. recently reported that local modes caused by antisite defects suppress $\kappa$ in $\mathrm{Bi}_{2} \mathrm{Te}_{2} \mathrm{Se}^{48}$

It may be possible to observe such a local mode in the low energy excitation spectrum. Fig. 4 shows low energy spectra obtained at $5 \mathrm{~K}$ with INS. The phonon spectrum was studied at $5 \mathrm{~K}$ to isolate changes from the graphite. The peak at $4 \mathrm{meV}\left(32 \mathrm{~cm}^{-1}\right)$ in the PDOS spectrum of pristine $\mathrm{Bi}_{2} \mathrm{Te}_{3}$ corresponds to both acoustic and optical modes ${ }^{49}$ and this region is modified by the introduction of graphite. There is no corresponding peak in the graphite density of states, demonstrating that the changes are not simply modes due to graphite. To emplasize this point, a Debye Plot i.e., variation of $\mathrm{g}(\mathrm{E}) / \mathrm{E}^{2}$ against Energy (E) is presented for the low energy region [Fig. 4 (inset)], which confirms that the introduction of graphite into the matrix

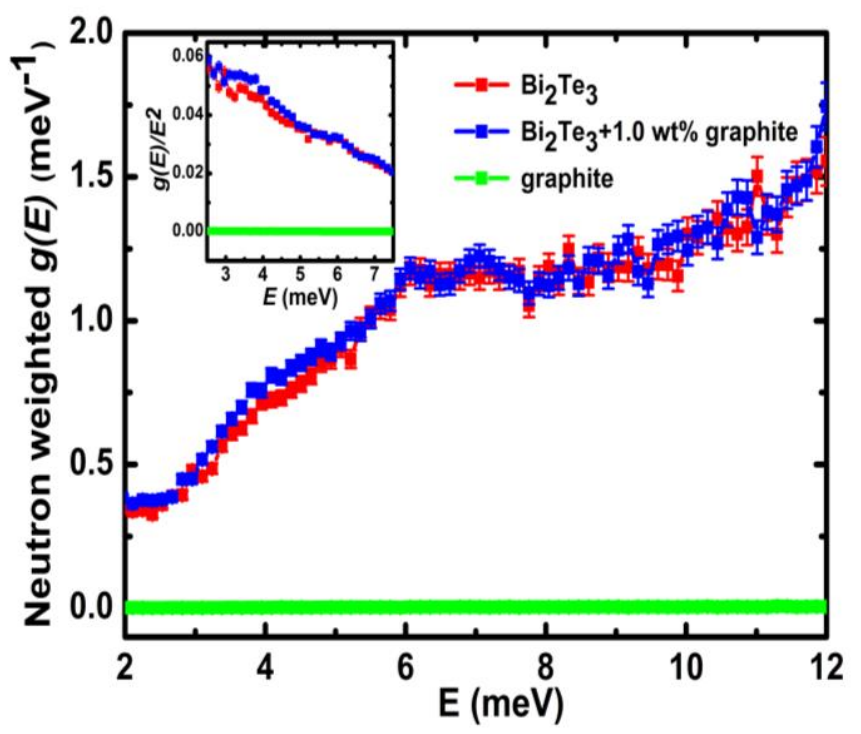

FIG. 4. Phonon density of states (PDOS) for pristine $\mathrm{Bi}_{2} \mathrm{Te}_{3}, \mathrm{Bi}_{2} \mathrm{Te}_{3}+1.0 \mathrm{wt} \%$ graphite and pure graphite. The low energy spectra have been integrated from 3 to $5 \AA^{-1}$. The pure graphite has been scaled by 0.005 based on the relative intensity of the graphite Bragg peaks present in the composite sample. (Inset) Debye level calculated from the specific PDOS measurement.

is indeed modifying the underlying $\mathrm{Bi}_{2} \mathrm{Te}_{3}$ PDOS. However, to say if this is truly due to local modes would require significant additional modeling, which is beyond the scope of the present paper.

The temperature dependent Seebeck Coefficient, $S$, for the $\mathrm{Bi}_{2} \mathrm{Te}_{3} /$ graphite nanocomposite samples is shown in Fig. 5. Negative values of $S$ imply that the samples are $n$-type in nature i.e., 
electrons are the majority carriers. For pristine $\mathrm{Bi}_{2} \mathrm{Te}_{3}$ the magnitude of $S$ increases gradually with increasing temperature, reaches a maximum at around $230 \mathrm{~K}$, and then slightly decreases with a further increase of temperature, which could be attributed to thermal excitation of minority carriers at high temperature. ${ }^{50}$ Similar $S(\mathrm{~T})$ data for single crystalline and thin films of $\mathrm{Bi}_{2} \mathrm{Te}_{3}$ have also been reported by other groups. ${ }^{51}$ Fig. 5 also reveals that $|S|$ of the composites increases with increasing graphite content, attaining the maximum value ( $105 \mu \mathrm{V} / \mathrm{K})$ for $\mathrm{Bi}_{2} \mathrm{Te}_{3}+1.0 \mathrm{wt} \%$ graphite $(\mathrm{x}=1.0)$ sample at around room temperature.

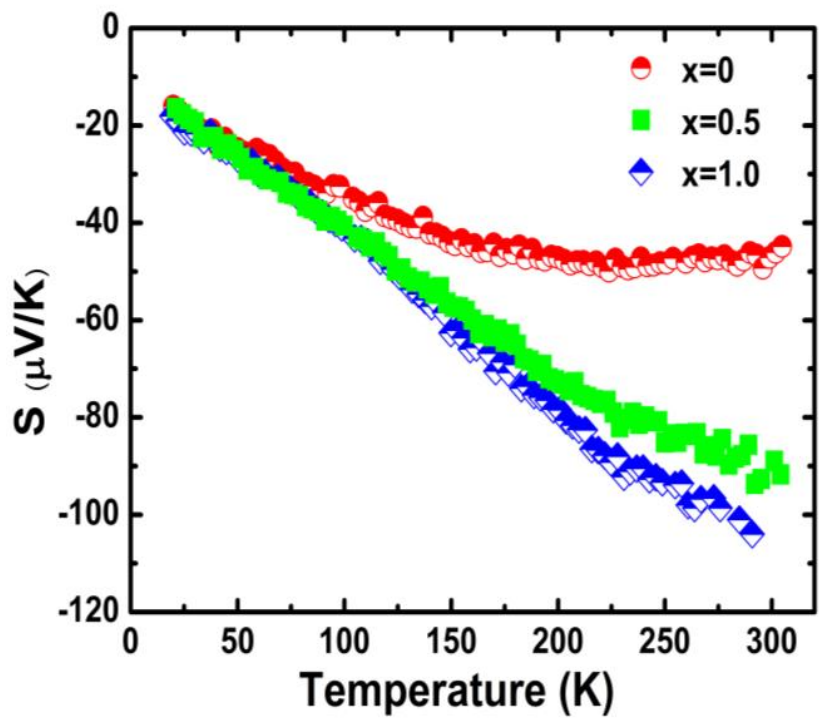

FIG. 5. Thermal variation of Seebeck Coefficient $(S)$ for different weight percentage $(\mathrm{x})$ of graphite in $\mathrm{Bi}_{2} \mathrm{Te}_{3} /$ graphite nanocomposites.

Incorporation of graphite nanoparticles changes the microstructure and the number of 1D channels in the composite samples. In addition, the Fermi level of the composite samples also changes with graphite addition. For pristine $\mathrm{Bi}_{2} \mathrm{Te}_{3}$ sample, it is possible to have some compensation of holes and electrons at room temperature. When Fermi level moves with adding graphite in composite we have only electrons, which is manifested in the linear behavior of the $\mathrm{S}(\mathrm{T})$ data in the composite samples. Pristine $\mathrm{Bi}_{2} \mathrm{Te}_{3}$ contains inherent defects like antisite defects and $\mathrm{V}_{\mathrm{Bi}}$, $\mathrm{V}_{\mathrm{Te}}$ type point defects, which act as scattering centers. The TeBi type antisite defect arising from excess Te occupying Bi sites and $\mathrm{V}_{\mathrm{Bi}}$ type point defects, are both $n$-type in nature, giving rise to the $n$-type behavior of the samples. The graphite in $\mathrm{Bi}_{2} \mathrm{Te}_{3} /$ graphite composites creates a higher defect density, which acts as additional scattering centers and affects the thermal transport of carriers. In addition, the increased density of hetero-interfaces and dislocations formed by randomly distributed graphite, inferred from the $\kappa(\mathrm{T})$ data of $\mathrm{Bi}_{2} \mathrm{Te}_{3}$ composites, also strongly scatter long and medium wavelength phonons. However, in 
order to confirm the impact of graphite on carrier and phonon scattering, the $S(\mathrm{~T})$ data in the low temperature regime (below Debye temperature, $\theta_{\mathrm{D}}$ ) have been fitted with the equation. ${ }^{52}$

$$
S=S_{0}+A_{1} T+A_{2} T^{3}
$$

Where $A_{1}=\frac{\pi^{2} k_{B}^{2}}{3|e| F}$ and $A_{2}=\frac{4 \pi^{4} k_{B}}{5|e| \theta_{D}}$. Here, $e$ is the charge of electron, and $F$ is the Fermi energy. As noted above, a simple semi-classical model may not be applicable to our samples (see later modeling), but may be used to the estimation of values. The A1T term arises due to diffusion thermopower, where electron-electron (e-e) mostly contributes. The parameter $\mathrm{A}_{2}$ is the coefficient of electron-phonon $(e-p h)$ scattering. The reported $\theta_{D}$ for $\mathrm{Bi}_{2} \mathrm{Te}_{3}$ is around $155 \mathrm{~K}^{42}$ The best fit values of $\mathrm{A}_{1}$ and $\mathrm{A}_{2}$, as extracted by fitting Eq. (3) with $S(\mathrm{~T})$ data for $\mathrm{Bi}_{2} \mathrm{Te}_{3} /$ graphite composites [see Fig. SM4 in the supplementary material], are provided in Table I. Both the scattering coefficients $A_{1}$ and $A_{2}$ increase with graphite content. It is thus evidenced that the addition of graphite plays a decisive role through $e$-e and e-ph phonon scattering, which in turn increases $S$ in the present $\mathrm{Bi}_{2} \mathrm{Te}_{3}$ based nanocomposite system. The importance of $e$ $e$ and $e-p h$ scattering in defect-induced $\mathrm{Sb}_{2} \mathrm{Te}_{3}$ system has been demonstrated earlier by our group. ${ }^{25}$ It has been shown for metal di-silicides, alloys, and doped $\mathrm{CoSb}_{3}$ based skutterudite compounds; the lower lattice thermal conductivity or better thermoelectric

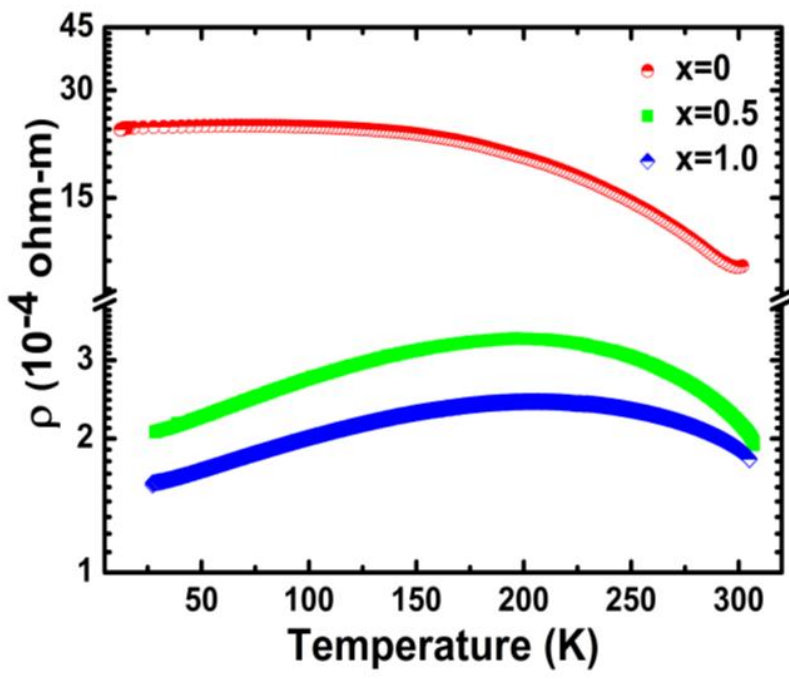

FIG. 6. Temperature dependent Resistivity $(\rho)$ for different weight percentage $(\mathrm{x})$ of graphite in $\mathrm{Bi}_{2} \mathrm{Te}_{3} /$ graphite nanocomposites. performance is likely due to point defect scattering and $e$-ph scattering. ${ }^{53}$ Enhanced $e-p h$ scattering was also experimentally verified in SiGe based TE materials. ${ }^{54}$ 
The $\rho(\mathrm{T})$ data of the $\mathrm{Bi}_{2} \mathrm{Te}_{3}+\mathrm{x}$ wt $\%$ graphite $(\mathrm{x}=0,0.5$, and 1.0) nanocomposite samples are presented in Fig. 6. Pristine $\mathrm{Bi}_{2} \mathrm{Te}_{3}$ shows semiconducting behavior i.e., $\rho$ decreases monotonically with increasing temperature. With graphite incorporation, $\rho(\mathrm{T})$ data of $\mathrm{Bi}_{2} \mathrm{Te}_{3} /$ graphite nanocomposites shows non-monotonic temperature dependence. For the synthesized nanocomposite samples, in the low temperature regime (up to $\sim 200 \mathrm{~K}$ ), $\rho$ increases with an increase of temperature, which is typical for a heavily doped semiconductor and could be explained by phonon scattering of charge carriers. ${ }^{13}$ At higher temperature, $\rho$ decreases as a function of temperature. The temperature dependence of $\rho(\mathrm{T})$ data could plausibly be explained by temperature dependence of carrier mobility $(\mu)$, which is because of the change in the scattering mechanism. Carrier mobility $(\mu)$, as estimated using $\rho(\mathrm{T})$ and $n_{H}(\mathrm{~T})$ data, changes non-monotonically with temperature [see Fig. SM5 in the supplementary material]. Fig. SM5 depicts that $\mu$ overall decreases with graphite dispersion.

The graphite dispersed in the $\mathrm{Bi}_{2} \mathrm{Te}_{3}$ matrix acts as a scattering center and impedes the mobility of the carrier. This leads to the

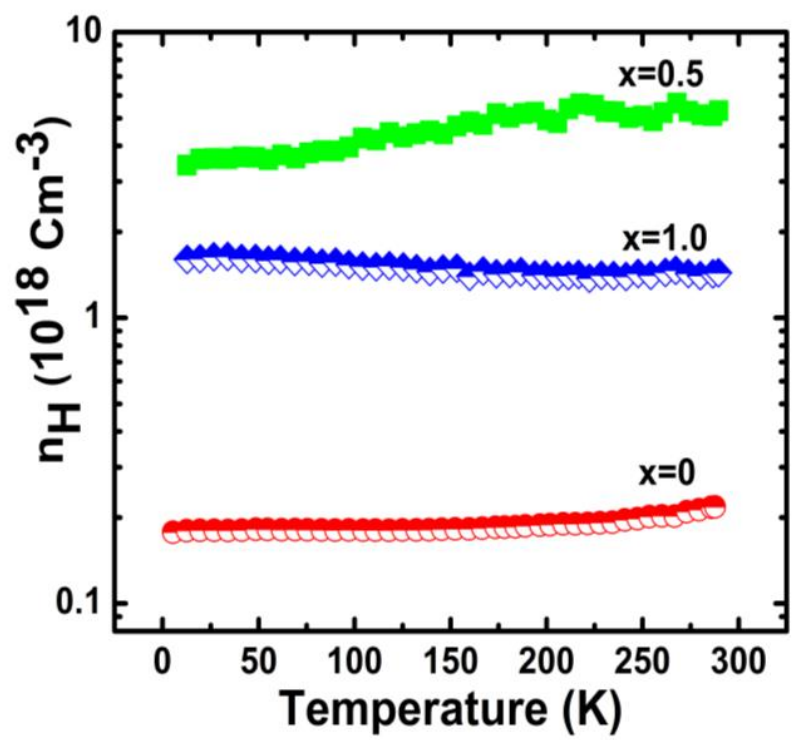

FIG. 7. Temperature dependent Carrier concentration $\left(n_{H}\right)$ for different weight percentage ( $\mathrm{x}$ ) of graphite in $\mathrm{Bi}_{2} \mathrm{Te}_{3} /$ graphite nanocomposites. The typical errors in $n_{H}$ value are within the size of the data points.

observed decrease of $\mu$ in the composite samples $(\mathrm{x}=0.5$ and 1.0) as compared to its pristine $(\mathrm{x}=0)$ counterpart. Most interestingly Fig. SM5 demonstrates that $\mu(\mathrm{T})$ shows similar temperature dependence for both the nanocomposite samples $(\mathrm{x}=0.5$ and 1.0$)$, probably due to owes to the microstructural changes arising from graphite dispersion in composite samples in contrast to the pristine $\mathrm{Bi}_{2} \mathrm{Te}_{3}$. 
Graphite creates additional defects in the grain boundary region of the synthesized nanocomposites, which could trap part of the charge carriers. With an increase of temperature, these carriers acquire sufficient thermal energy and get delocalized. However, with an increase of graphite content, the number of defects at the grain boundaries increases, trapping a higher number of charge carriers. This corroborates with the $n_{H}$ data, where $n_{H}$ decreases with increase of graphite content from $\mathrm{x}=0.5$ to $\mathrm{x}=1.0$ [Fig. 7]. Besides, Fig. 6 demonstrates that $\rho$ decreases systematically with increasing graphite content. The electrical conductivity of graphite is quite high, as compared to $\mathrm{Bi}_{2} \mathrm{Te}_{3}$. The decrease of $\rho$ with increasing graphite content in $\mathrm{Bi}_{2} \mathrm{Te}_{3} /$ graphite nanocomposites could possibly be explained by the high electrical conductivity of graphite. ${ }^{22}$ The $n_{H}$ data also indicate that graphite substantially increases the electron concentration [Fig. 7]. Furthermore, as demonstrated by Banik et al. ${ }^{43}$ for $\mathrm{Sb}$ doped $\mathrm{SnTe}$, it could be assumed that in the reported nanostructured $\mathrm{Bi}_{2} \mathrm{Te}_{3} /$ graphite composites, graphite particles are coherently distributed in the matrix. Such coherent interfaces contribute towards long- and medium-wavelength phonon scattering, while maintaining good carrier transport, without excessive scattering leading to the observed decrease of $\rho$ with graphite incorporation. ${ }^{55}$

To highlight the underlying transport mechanism in the synthesized $\mathrm{Bi}_{2} \mathrm{Te}_{3} /$ graphite nanocomposite samples, thermoelectric parameters, viz., $\rho(\mathrm{T}), S(\mathrm{~T})$ and $\kappa_{e}(\mathrm{~T})$ are theoretically simulated. The electron parameters, as obtained using experimentally measured $n_{H}(\mathrm{~T})$ and $\sigma(\mathrm{T})$ data for $0.1 \mathrm{~m}_{0}$ effective mass, are provided in Table-II. Table-II divulges that Ioffe-Regel criterion, i.e., the mean electron (hole) wavelength should be smaller than electron (hole) mean free path, is not fulfilled. Unrealistically small estimate of mean free path $(l)$ results, mainly due to an anomaly in small electrical conductivity, $\sigma$. The small value of $\sigma$ can be due to limitation of electron transport between $\mathrm{Bi}_{2} \mathrm{Te}_{3}$ nanocrystals. We suggest that the contacts between nanocrystals behave as one dimensional (1D) transport channels. The length of such channel should be less than electron mean free path. Therefore electron transport within the channel should be ballistic. In the simplest model, a 
composite can be considered as a network of resistors representing 1D channel. The conductivity, $g$ of $1 \mathrm{D}$ channel can be calculated as: ${ }^{56}$

$$
g=\frac{e^{2}}{\pi \hbar} \frac{1}{\exp \left(\frac{E_{1}-F}{k_{B} T}\right)+1},
$$

where, $e$ is elementary charge, $\hbar$ is the Plank constant, $E_{1}$ is the minimum electron energy in $1 \mathrm{D}$ channel, $F$ is Fermi energy, $k_{B}$ is Boltzmann constant, $T$ is the temperature.

The $\sigma$ of the network (composite) can be estimated as:

$$
\sigma=g / l,
$$

Where, $l$ is the typical size and $\mathrm{g}$ is the conductance of single 1D transport channel network.

The Seebeck coefficient for ballistic transport in 1D transport channel can be calculated in similar way assuming that heat transport is also limited by contacts. For single 1D channel, the following expression for the Seebeck coefficient was obtained: ${ }^{56-58}$

$$
S=-\frac{k_{B}}{e}\left(\frac{E_{1}-F}{k_{B} T}+\left(\exp \left(\frac{E_{1}-F}{k_{B} T}\right)+1\right) \ln \left(1+\frac{F-E_{1}}{k_{B} T}\right)\right),
$$

Assuming that all 1D channels in the network are the same, we get a Seebeck coefficient for the network (composite) equal to the Seebeck coefficient for single channel.
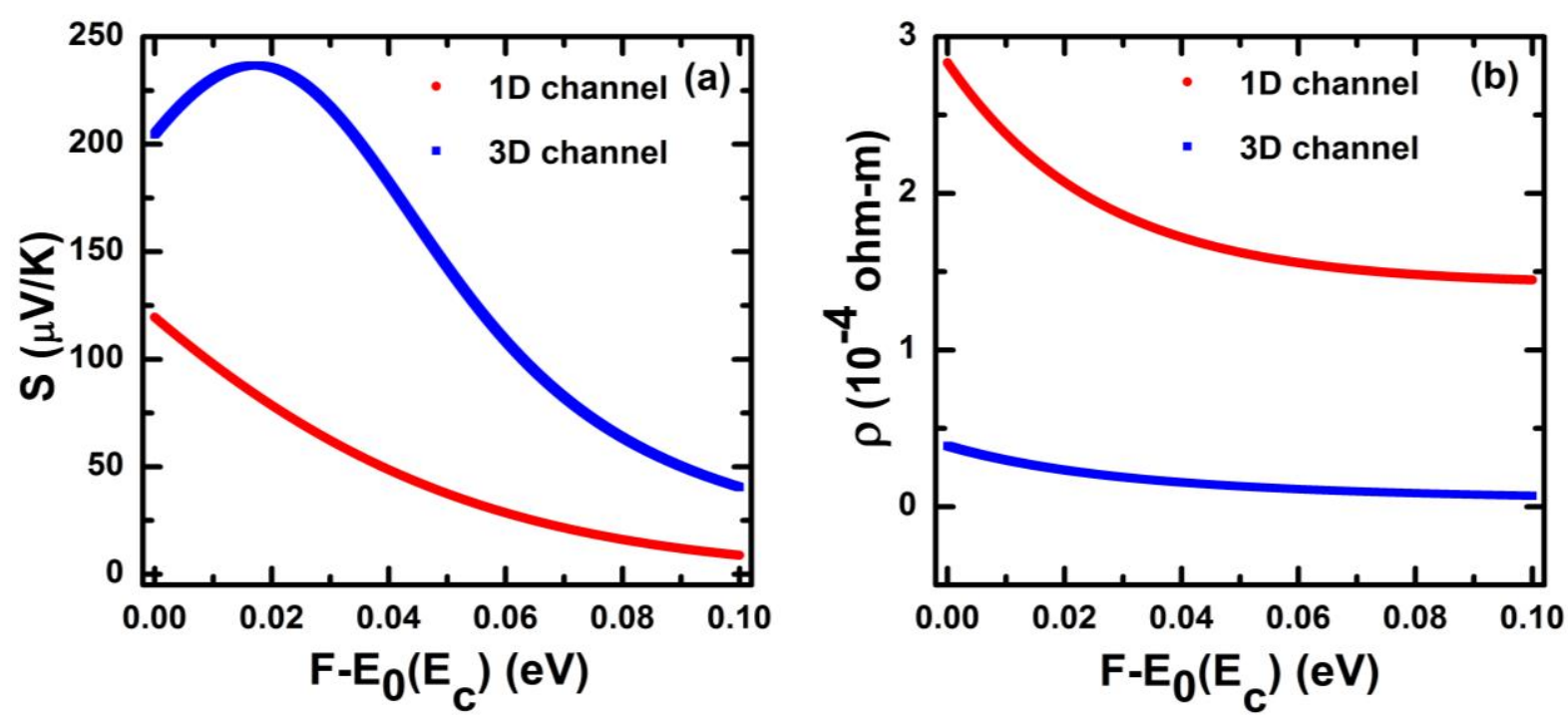

FIG. 8. Dependence of (a) Seebeck coefficient, $S$; and (b) resistivity, $\rho$ on the position of Fermi level with respect to $\mathrm{E}_{0}$ at $300 \mathrm{~K}$ for single band $1 \mathrm{D}$ and $3 \mathrm{D}$ electron transport. 
For electronic contributions to the heat conductance, $K_{e}$ of a single $1 \mathrm{D}$ channel, the following expression can be derived for ballistic electron transport in the case $\frac{F-E_{1}}{k_{B} T}>1:^{56-58}$

$$
K_{e}=\frac{k_{B}}{\pi \hbar}\left(2 k_{B} T\left(1+\int_{0}^{\infty} \frac{x d x}{\exp (x)+1}\right)-\left(F-E_{1}\right)\left(\exp \left(\frac{E_{1}-F}{k_{B} T}\right)-e S\right)\right),
$$

The electronic contribution to the heat conductivity of a network of 1D channels (composite), $\kappa_{e}$ can be estimated as:

$$
\kappa_{e}=K_{e} / l
$$

The dependence of the Seebeck coefficient and resistivity on the position of the Fermi level with respect to $E_{0}$ at $300 \mathrm{~K}$ is plotted in Fig. 8. In this calculation, we assume $l=d$, where $d$ is the mean size of a $\mathrm{Bi}_{2} \mathrm{Te}_{3}$ grain. It seems that reasonable quantitative agreement between calculated and experimental values can be achieved for $\mathrm{F}_{-} \mathrm{E}_{0} \approx 0.02 \mathrm{eV}$.

For comparison, we also plot similar dependencies of conductivity and Seebeck coefficient calculated for single band 3D electron transport with constant electron mean free path equal to $d:{ }^{57,58}$

$$
\begin{gathered}
\sigma=\frac{2 e^{2} v d m k_{B} T}{3 \pi^{2} \hbar^{3}} \ln \left(1+\exp \left(\frac{F-E_{C}}{k_{B} T}\right)\right), \\
S=\frac{0 \int_{0}^{\infty} \frac{x d x}{\exp (x)+1}+\frac{F-E_{C}}{k_{B} T} \ln \left(1+\exp \left(\frac{F-E_{C}}{k_{B} T}\right)\right)-2 \int_{0}^{\frac{F-E_{C}}{k_{B} T}} \frac{x d x}{\exp (x)+1}}{\ln \left(1+\exp \left(\frac{F-E_{C}}{k_{B} T}\right)\right)},
\end{gathered}
$$

where $v=6$ is the valley degeneracy, $m$ is conduction band effective mass, $E_{C}$ is the conduction band minimum. Expressions (9-10) were derived from steady state solution of Boltzmann equation for electrons in the relaxation time approximation..$^{57,58}$ For calculation we took $m=0.1 m o, m_{0}$ is free electron effective mass. The Fermi level position is calculated from the neutrality equation: 


$$
N_{d}=\frac{6 \sqrt{2}\left(m k_{B} T\right)^{3 / 2}}{\pi^{2} \hbar^{3}} \int_{0}^{\infty} \frac{x^{1 / 2} d x}{\exp \left(x-\frac{F-E_{C}}{k_{B} T}\right)+1}
$$

where, donor concentration is equal to $N_{d}$. It is seen that using the $3 \mathrm{D}$ transport model, the calculated Seebeck coefficient is much larger and the resistivity is much smaller than the experimental value.

Thus, the relatively small experimental value of the Seebeck coefficient and electrical conductivity can be explained by the limitations of electron transport by contacts between $\mathrm{Bi}_{2} \mathrm{Te}_{3}$ nanocrystals. Reasonable quantitative agreement with experimental data is obtained within a simple model assuming ballistic electron transport in 1D channels.

The temperature dependence of the Fermi energy, $F$ is required to model $S(\mathrm{~T})$ and $\rho(\mathrm{T})$ data. To calculate such dependence, we assume that the position of $F$ is determined by donor concentration and two-dimensional topology protected surface at the surface of $\mathrm{Bi}_{2} \mathrm{Te}_{3}$ grains. Further, we suggest that $F$ is located above the Dirac point $\left(\mathrm{E}_{2}\right)$ at all temperatures and $\frac{F-E_{2}}{k_{B} T}>>1$. In this case, we neglect holes in dispersion law $E-E_{2}= \pm v_{0} p$, where $v_{0}$ is the constant with dimension of velocity, and $p$ is is momentum. The electron concentration $\left(n_{H}\right)$ can be calculated as: 57,58

$$
n_{H} \approx \frac{\left(k_{B} T\right)^{2} S_{g s}}{2 \pi \hbar^{2} v_{0}^{2} d^{3}}\left(\int_{0}^{\infty} \frac{x d x}{\exp (x)+1}-\left(\frac{F-E_{2}}{k_{B} T}\right)^{2}\right)
$$

Where $S_{g s}$ is the grain surface area carrying 2D topologically protected states.

Assuming that all the donors are ionized at all temperatures, we obtain the following expression for the temperature dependence of the Fermi energy: 


$$
F=E_{2}+\sqrt{\frac{4 \pi \hbar^{2} v_{0}^{2} d^{3} N_{d}}{S_{g s}}-2\left(k_{B} T\right)^{2} \int_{0}^{\infty} \frac{x d x}{\exp (x)+1}},
$$

We assume $S_{g s}=d^{2}$ and $l=d=11 \mathrm{~nm}$ and use calculated values of the Seebeck coefficient, $S$; electrical resistivity, $\rho$; and electronic part of thermal conductivity, $\kappa_{e}$ for the sample with $1.0 \mathrm{wt} \%$ graphite taking $\mathrm{N}_{\mathrm{d}}=1.5 \times 10^{18} \mathrm{~cm}^{-3}$ and $\mathrm{E}_{1}-\mathrm{E}_{2}$ as a fitting parameter. The results are plotted in Fig. 9 by solid lines for $\mathrm{E}_{1}-\mathrm{E}_{2}=0.135 \mathrm{eV}$.

Reasonable quantitative agreement with experiment is achieved for the sample with $1.0 \mathrm{wt} \%$ graphite content within the simplified approach described above. A similar agreement for the sample with $0 \mathrm{wt} \%$ and $0.5 \mathrm{wt} \%$ graphite content can be achieved only by independent variation of $S_{g s}, l$, and $\mathrm{E}_{1}-\mathrm{E}_{2}$. For the sample with $0.5 \mathrm{wt} \%$ graphite, reasonable agreement with experiment can be achieved for relatively small (less than 30\%) deviation of $l$ from $d$ and $S_{g s}$ from $d^{2}$. For the sample with 0 wt $\%$ graphite $l$ needs to be larger than $d$, and $S_{g s}$ smaller than $d^{2}$, to achieve reasonable agreement between experimental and calculated values of Seebeck coefficient and resistivity. These

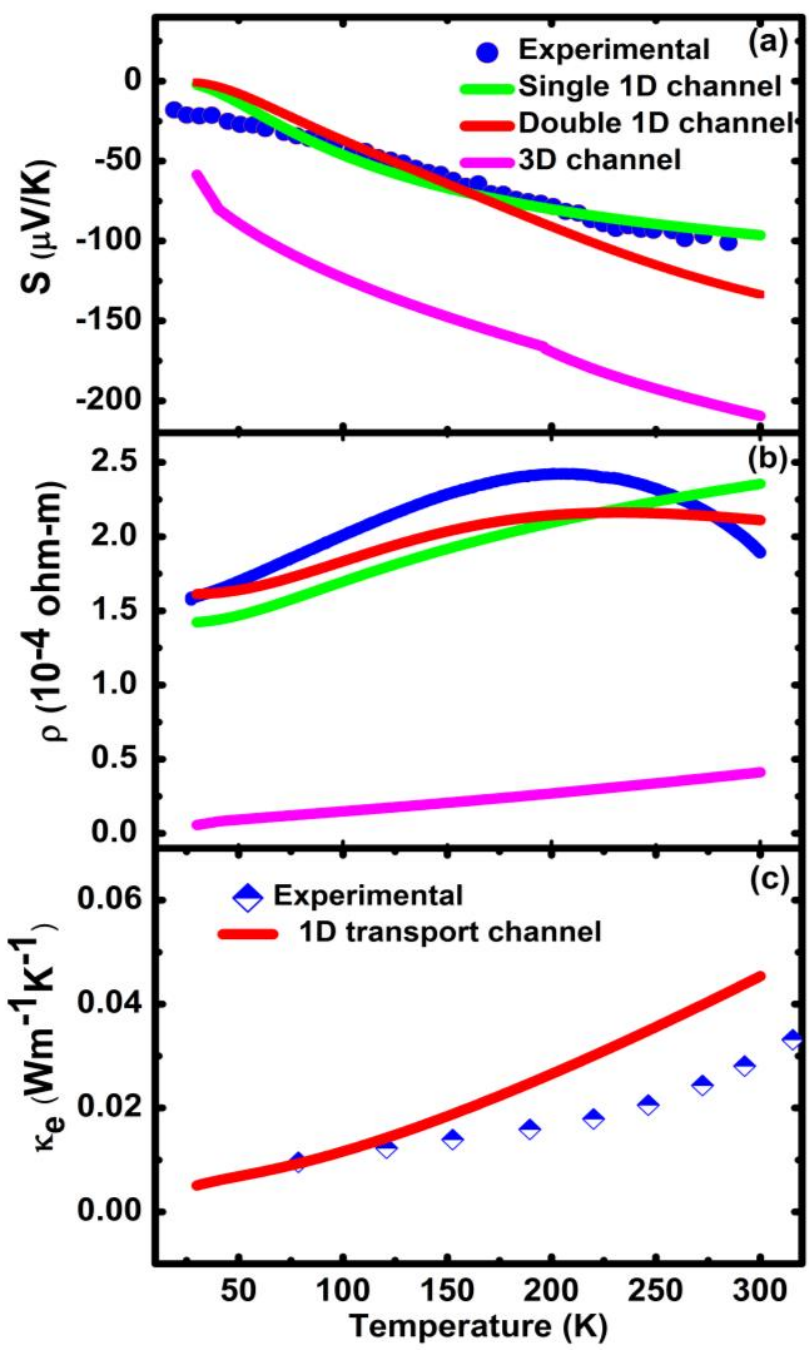

FIG. 9. Temperature dependencies of (a) Seebeck coefficient, $S ; \quad($ b) electrical resistivity, $\rho$; experimental (points), simulated (single 1D channel, double 1D channel and 3D transport model) and (c) electronic part of thermal conductivity, $\kappa_{e}$ experimental (points) and simulated (1D transport model) results of $\mathrm{Bi}_{2} \mathrm{Te}_{3}+1.0 \mathrm{wt} \%$ graphite nanocomposite sample.

observations point to possible differences between the microstructure of pristine $\mathrm{Bi}_{2} \mathrm{Te}_{3}$ and composite samples containing graphite dispersoids and corroborate the carrier mobility data [Fig. 
SM5]. However the simplified theoretical model assuming single 1D transport channels does not reproduce the maximum in the temperature dependence of resistivity. In the model we assumed that all 1D channels in the contact network have the same energy, $E_{1}$. In fact, there has to be broad distribution of these energies. A significant part of the 1D sub bands in the channels should have energies higher than Fermi energy. Thermal activation of electrons to these 1D sub bands should increase at higher temperature. To illustrate this, we also calculated the electrical resistivity and Seebeck coefficient for two networks of $1 \mathrm{D}$ channels with sizes $l_{1}=12.5 \mathrm{~nm}$ and $l_{2}=5 \mathrm{~nm}$ and energies $E_{1}$ and $E_{3}$ with $E_{1}-E_{2}=0.132 \mathrm{eV}, E_{3}-E_{2}=0.220 \mathrm{eV}$. The theoretically simulated results using two groups of 1D transport channel with different energies are shown in fig. 9. The following expressions have been used: ${ }^{56-58}$

$$
\begin{gathered}
\sigma=\frac{e^{2}}{\pi \hbar} \sum_{k=0}^{1} \frac{1}{l_{k+1}} \frac{1}{\exp \left(\frac{E_{1+2 \mathrm{k}}-F}{k_{B} T}\right)+1}, \\
S=-\frac{k_{B}}{e} \frac{\sum_{k=0}^{1} \frac{1}{l_{k+1}}\left\{\frac{\frac{E_{1+2 \mathrm{k}}-F}{k_{B} T}}{\left[\exp \left(\frac{E_{1+2 \mathrm{k}}-F}{k_{B} T}\right)+1\right]}+\ln \left[1+\exp \left(\frac{F-E_{1+2 \mathrm{k}}}{k_{B} T}\right)\right]\right\}}{\sum_{k=0}^{1}\left[\exp \left(\frac{E_{1+2 \mathrm{k}}-F}{k_{B} T}\right)+1\right]},
\end{gathered}
$$

The maximum in the temperature dependence of resistivity is reproduced, in reasonable agreement with experiment. The agreement between modeled and measured temperature dependence of seebeck coefficient is also reasonable.

The $Z T$ value, estimated using the $\rho(\mathrm{T}), S(\mathrm{~T})$ and $\kappa(\mathrm{T})$ data, increases with increasing temperature [see Fig. SM6 in the supplementary material]. Furthermore, graphite addition plays a 
positive role towards the betterment of all the crucial TE parameters, i.e., S, $\kappa$, and $\rho$ and is reflected in the $Z T$ data of the composite samples, which also increases with increasing graphite dispersion. A substantial increase of $Z T$ is observed in the highest graphite content $(x=1.0)$ nanocomposite sample compared to its pristine $(\mathrm{x}=0)$ counterpart. However, it should be emphasized that the non-optimized carrier concentration in the samples reported here leads to the observed low ZT value, which is presented in the supplementary material. It is notable that graphite addition simultaneously improves all the TE parameters, viz., $\rho, S$, and $\kappa$. $\mathrm{Bi}_{2} \mathrm{Te}_{3}$ nanocrystals anchored on a single-walled carbon nanotube have recently been reported as an excellent route for the design and fabrication of highperformance flexible thermoelectric materials. ${ }^{59}$ Our results also clearly indicate that nanocompositing with graphite, which is also a carbon-based material, is a favourable route for improving TE performance in $\mathrm{Bi}_{2} \mathrm{Te}_{3}$ based thermoelectrics. The enhanced TE performance can be obtained by applying this approach to similar nanocomposite systems. The impact of graphite dispersion on various TE material/graphite nanocomposites by tuning the graphite content should be investigated further.

\section{CONCLUSION}

Thermoelectric properties of nanostructured n-type $\mathrm{Bi}_{2} \mathrm{Te}_{3} /$ graphite composites have been investigated both experimentally and theoretically. In depth characterization of the synthesized nanocomposites samples is carried out using powder XRD diffraction, Raman spectroscopic analysis, temperature dependence of thermal conductivity, $\kappa(\mathrm{T})$; thermopower, $S(\mathrm{~T})$; electrical resistivity, $\rho(\mathrm{T})$ and Hall concentration, $n_{H}(\mathrm{~T})$. Rietveld refinement of the XRD data reveals that graphite inhibits the grain growth and increases lattice strain in the $\mathrm{Bi}_{2} \mathrm{Te}_{3}$ matrix. Raman spectroscopic analysis confirms the presence of graphite in the composite samples. In addition, the appearance of Raman active peaks associated with graphite in the Raman spectra, indicates the presence of defects and disorder in the system, which further helps in scattering phonons. Graphite dispersion significantly decreases $\kappa$ of the nanocomposite samples. $\kappa L(T)$, as extracted from $\kappa(\mathrm{T})$ 
data, follows a similar temperature and graphite dependence to that of $\kappa(\mathrm{T})$. A low $\kappa_{L}$ value of 0.77 $\mathrm{Wm}^{-1} \mathrm{~K}^{-1}$ is reported for $\mathrm{Bi}_{2} \mathrm{Te}_{3}+1.0 \mathrm{wt} \%$ graphite composite sample. The role of graphite in introducing effective scattering sources, viz., OD point defects, 1D dislocations, and 2D heterointerfaces for scattering phonons of different wavelengths is discussed in terms of the substantial (17\%) decrease of $\kappa_{L}$ with graphite incorporation in pristine $\mathrm{Bi}_{2} \mathrm{Te}_{3}$. In this context, the contribution of graphite in introducing local low energy optical phonon modes and its interaction with acoustical phonons towards achieving low phonon group velocity $\left(v_{g}\right)$ is also emphasized. Such a local mode is observed in the low-energy spectrum obtained by Inelastic Neutron Scattering (INS). The peak in the INS spectra corresponding to acoustic and optical modes of pristine $\mathrm{Bi}_{2} \mathrm{Te}_{3}$ is altered by graphite addition. This furthermore indicates that the Phonon Density of States (PDOS) of $\mathrm{Bi}_{2} \mathrm{Te}_{3}$ is modified with graphite incorporation and plays a positive role in phonon scattering. An improvement in Seebeck coefficient with graphite incorporation is also observed. The electrical conductivity of the $\mathrm{Bi}_{2} \mathrm{Te}_{3} /$ graphite nanocomposite system also increases systematically with increasing graphite content and corroborates the measured Hall concentration data. Simultaneous improvement of all the crucial TE parameters, viz., $\rho, S$, and $\kappa$ with graphite dispersion leads to an increase in ZT of the reported nanocomposite samples. Reasonable agreement with the experimental $\rho(\mathrm{T}), S(\mathrm{~T})$, and $\kappa e(\mathrm{~T})$ data for a $\mathrm{Bi}_{2} \mathrm{Te}_{3}+1.0 \mathrm{wt} \%$ graphite composite sample is obtained with the theoretical model assuming ballistic electron transport in two groups of $1 \mathrm{D}$ channel between $\mathrm{Bi}_{2} \mathrm{Te}_{3}$ nanocrystals. The theoretical simulation further indicates the microstructural difference between pristine $\mathrm{Bi}_{2} \mathrm{Te}_{3}$ and composite samples with graphite dispersoids, as a possible reason for realizing excellent thermoelectric performance in nanostructured $\mathrm{Bi}_{2} \mathrm{Te}_{3} /$ graphite composites with optimized charge-carrier concentrations. 


\section{SUPPLEMENTARY MATERIAL}

See the supplementary material for the details of X-ray diffraction patterns after Rietveld refinement along with the refinement parameters obtained using MAUD software, high resolution TEM image of $\mathrm{Bi}_{2} \mathrm{Te}_{3}+1 \mathrm{wt} \%$ graphite nanocomposite sample, Dislocation density $\left(N_{D}\right)$, porosity correction of temperature dependence thermal conductivity $(\kappa)$, fitting of temperature dependent thermopower data, temperature dependence of carrier mobility and $\mathrm{ZT}$ of $\mathrm{Bi}_{2} \mathrm{Te}_{3}+\mathrm{x} w \mathrm{t} \%$ graphite $(\mathrm{x}=0,0.5$, and 1.0) samples.

\section{ACKNOWLEDGMENTS}

The work is supported by UGC DAE CSR, Kolkata centre, Govt. of India (Project reference no.: UGC-DAE-CSR-KC/CRS/19/MS02/0939) and Inter-University Accelerator Centre (IUAC), New Delhi, Govt. of India (Project code no.: UFR-65307). Author PS is gratefful to UGC DAE CSR, Kolkata centre, Govt. of India for providing financial assistance in the form of research fellowship and author SD is thankful to UGC, Govt. of India for providing him Research Fellowship. The authors are grateful to Dr. S Bhattacharya, BARC, India for providing necessary facilities (hot-press) towards sample synthesis. Authors are thankful to Prof. Sandip Dhara, IGCAR, India for the Raman spectroscopy measurement. Authors would also like to thank DST, India for the financial support, JNCASR, India for facilitating the experiments (INS) at the RAL, ISIS, UK. We also thank STFC for access to neutron scattering facilities through the beam time allocation on MARI (https://doi.org/10.5286/ISIS.E.RB1868011).

\section{DATA AVAILABILITY}

The data that supports the findings of this study are available within the article and its supplementary material. 


\section{$\underline{\text { References }}$}

${ }^{1}$ G. J. Snyder and E. S. Toberer, Nat. Mater. 7, 105 (2008).

${ }^{2}$ M. S. Dresselhaus, G. Chen, M. Y. Tang, R. Yang, H. Lee, D. Wang, Z. Ren, J. -P. Fleurial, and

P. Gogna, Adv. Mater. 19, 1043 (2007).

${ }^{3}$ L. E. Bell, Science 321, 1457 (2008).

${ }^{4}$ J. Zhang, D. Wu, D. He, D. Feng, M. Yin, X. Qin, and J. He, Adv. Mater. 29, 1703148 (2017).

5. Chen, X. Zhang, and Y. Pei, Adv. Mater 30, 1705617 (2018).

${ }^{6}$ J. -H. Bahk, Z. Bian, and A. Shakouri, Phys. Rev. B 87, 075204 (2013).

${ }^{7}$ G. Nolas, L. M. Woods, and R. Funahashi, J. Appl. Phys. 127, 060401 (2020).

${ }^{8}$ K. Behnia, Fundamentals of Thermoelectricity (Oxford University Press, Oxford, 2015).

${ }^{9}$ A. I. Hochbaum, R. Chen, R. D. Delgado, W. Liang, E. C. Garnett, M. Najarian , A. Majumdar, and P. Yang, Nature 451, 163 (2008).

${ }^{10}$ L. D. Hicks and M. S. Dresselhaus, Phys. Rev. B 47, 12727 (1993); L. D. Hicks, T. C. Harman, X. Sun, and M. S. Dresselhaus, Phys. Rev. B 53, R10493 (1996).

${ }^{11}$ B. Poudel, Q. Hao, Yi. Ma, Y. Lan, A. Minnich, B. Yu, X. Yan, D. Wang, A. Muto, D.

Vashaee, X. Chen, J. Liu, M. S. Dresselhaus, G. Chen and Z. Ren. Science 320, 634 (2008).

${ }^{12}$ K. T. Kim, S. Y. Choi, E. H. Shin, K. S. Moon, H. Y. Koo, G-G Lee, and G. H. Ha, Carbon 52, 541 (2013).

${ }^{13}$ V.D. Blank, S.G. Buga, V.A. Kulbachinskii, V.G. Kytin, V.V. Medvedev, M.Yu. Popov, P.B. Stepanov, and V. F. Skok, Phys. Rev. B 86, 075426 (2012); V. A. Kulbachinskii, V. G. Kytin, M. Y. Popov, S. G. Buga, P. B. Stepanov, and V. D. Blank, J. Solid State Chem. 193, 64 (2012); V. A. Kulbachinskiia, V. G. Kytin, V. D. Blank, S. G. Buga, and M. Yu. Popov, Semiconductors, 45, 1194 (2011).

${ }^{14}$ K. Agarwal, V. Kaushik, D. Varandani, A. Dhar, and B.R. Mehta, J. Alloys Compd. 681, 394 (2016).

${ }^{15}$ N. Satyala, A. T. Rad, Z. Zamanipour, P. Norouzzadeh, J. S. Krasinski, L. Tayebi, and D. Vashaee, J. Appl. Phys. 115, 044304 (2014).

${ }^{16}$ J. Gainza, F. Serrano-Sánchez, M. Gharsallah, F. Carrascoso, J. Bermúdez, O. J. Dura , F. J. Mompean, N. Biskup, J. J. Meléndez , J. L. Martínez , J. A. Alonso , and N. M. Nemes, J. Appl. Phys. 126, 045501 (2019).

${ }^{17}$ Y. Lan, B. Poudel, Y. Ma, D. Wang, M. S. Dresselhaus, G. Chen, and Z. Ren, Nano Lett. 9, 
1419, (2009).

${ }^{18}$ G. S. Nolas, J. Sharp and H. J. Goldsmid, Thermoelectrics: Basic principles and New materials Developments, Springer (2001).

${ }^{19}$ Y. L. Chen, J. G. Analytis, J.-H. Chu, Z. K. Liu, S.-K. Mo, X. L. Qi, H. J. Zhang, D. H. Lu, X.

Dai, Z. Fang, S. C. Zhang, I. R. Fisher, Z. Hussain, Z. -X. Shen, Science 325, 178 (2009).

${ }^{20}$ R. Venkatasubramanian, E. Siivola, T. Colpitts and B. O'Quinn, Nature 413, 597 (2001).

${ }^{21}$ S. Das, P. Singha, A. K. Deb, S. C. Das, S. Chatterjee, V. A. Kulbachinskii, V. G. Kytin, D. A. Zinoviev, N. V. Maslov, S. Dhara, S. Bandyopadhyay, and A. Banerjee, J. Appl. Phys. 125, 195105 (2019).

${ }^{22}$ H. O. Pierson, Handbook of Carbon, Graphite, Diamond and Fullerenes: Properties, Processing and Applications (Noyes Publications, Park Ridge, NJ, 1994). D. D. L. Chung, J. Mater. Sci. 37, 1475 (2002).

${ }^{23}$ K. Malik, D. Das, D. Mondal, D. Chattopadhyay, A. K. Deb, S. Bandyopadhyay, and A. Banerjee, J. Appl. Phys. 112, 083706 (2012). J. G. M. Van Berkum, G. J. M. Sprong, Th. H. de Keijser, R. Delhez, and E. J. Sonneveld, Powder Diffr. 10, 129 (1995).

${ }^{24}$ L. Lutterotti, S. Matthies, and H. R. Wenk, in Proceeding of ICOTOM14, edited by J. A. Spunar (National Research Council of Canada, Ottawa, 1999), p.1599; IUCr: Newsl. CPD 21, 14 (1999). ${ }^{25}$ D. Das, K. Malik, A. K. Deb, S. Dhara, S. Bandyopadhyay, and A. Banerjee, J. Appl. Phys. 118, $045102(2015)$.

${ }^{26}$ D. Das, K. Malik, A. K. Deb, V. A. Kulbachinskii, V. G. Kytin, S. Chatterjee, D. Das, S. Dhara, S. Bandyopadhyay, and A. Banerjee, Europhys Lett. 113, 47004 (2016).

${ }^{27}$ V. A. Kulbashinskii, V. G. Kytin, N. V. Maslov, P. Singha, S. Das, A. K. Deb, and A. Banerjee, Materials Today: Proceedings 8, 573 (2019).

${ }^{28}$ J. Taylor, O. Arnold, J. Bilheaux, A. Buts, S. Campbell,..., and J. Zikovsky Mantid, A high performance framework for reduction and analysis of neutron scattering data. Bulletin of the American Physical Society 57, (2012).

${ }^{29}$ N. C. Popa, J. Appl. Cryst. 31, 176 (1998).

${ }^{30}$ Q. Zhang, L. Xu, Z. Zhou, L. Wang, W. Jiang, and L. Chen, J. Appl. Phys. 121, 055104 (2017). Q. Huang, Y. Bando, X. Xu, T. Nishimura, C. Y. Zhi, C. C. Tang, F. F. Xu, L. Gao, and D. Golberg, Nanotechnology 18 (48), 485706 (2007).

${ }^{31}$ X. Liu, D. J. Smith, J. Fan, Y.-H. Zhang, H. Cao, Y. P. Chen, J. Leiner, B. J. Kirby, M.

Dobrowolska, and J. K. Furdyna, Appl. Phys. Lett. 99, 171903 (2011). 
${ }^{32}$ K. M. F. Shahil, M. Z. Hossain, D. Teweldebrhan, and A. A. Balandin, Appl. Phys. Lett 96, 153103 (2010); K. M. F. Shahil, M. Z. Hossain, V. Goyal, and A. A. Balandin, J. Appl. Phys. 111, 054305 (2012).

${ }^{33}$ P. Puneet, R. Podila, M. Karakaya, S. Zhu, J. He, T. M. Tritt, M. S. Dresselhaus, and A. M. Rao, Sci. Rep. 3, 3212 (2013).

${ }^{34}$ R. Saito, M. Hofmann, G. Dresselhaus, A. Jorio, and M.S. Dresselhaus, Adv Phys. 60, 413 (2011).

${ }^{35}$ A. C. Ferrari, J. C. Meyer, V. Scardaci, C. Casiraghi, M. Lazzeri, F. Mauri, S. Piscanec, D. Jiang, K. S. Novoselov, S. Roth, and A. K. Geim, Phys Rev Lett. 97, 187401 (2006).

${ }^{36}$ H.-S. Kim, Z. M. Gibbs, Y. Tang, H. Wang, and G. J. Snyder, APL Mater. 3, 041506 (2015).

${ }^{37}$ N. Satyala, A. T. Rad, Z. Zamanipour, P. Norouzzadeh, J. S. Krasinski, L. Tayebi, and D. Vashaee, J. Appl. Phys. 115, 044304 (2014).

${ }^{38}$ O. Meroz, N. Elkabets, and Y. Gelbstein, ACS Appl. Energy Mater. 3, 2090 (2020).

${ }^{39}$ B. Zhu, X. Liu, Q. Wang, Y. Qiu, Z. Shu, Z. Guo, Y. Tong, J. Cui, M. Gu, and J. He, Energy Environ. Sci. 13, 2106 (2020).

${ }^{40}$ K. Biswas, J. He, I. D. Blum, C.-I. Wu, T. P. Hogan, D. N. Seidman, V. P. Dravid, and M. G. Kanatzidis, Nature 489, 414 (2012).

${ }^{41}$ D. G. Cahill and R. O. Pohl, Annu. Rev. Phys. Chem. 39, 93 (1988).

${ }^{42}$ P. Wei, J. Yang, L. Guo, S. Wang, L. Wu, X. Xu, W. Zhao, Q. Zhang, W. Zhang, M. S. Dresselhaus, and J. Yang, Adv. Funct. Mater. 26, 5360 (2016).

${ }^{43}$ A. Banik, B. Vishal, S. Perumal, R. Datta, and K. Biswas, Energy Environ. Sci. 9, 2011 (2016).

${ }^{44}$ N. W. Ashcroft and N. D. Mermin, Solid State Physics (Brooks/Cole, Pacific Grove, CA, 1976).

45. Q. He, S. N. Girard, M. G. Kanatzidis, V. P. Dravid, Adv. Funct. Mater. 20, 764 (2010).

${ }^{46}$ G. Tan, F. Shi, S. Hao, L.-D. Zhao, H. Chi, X. Zhang, C. Uher, C. Wolverton, V. P. Dravid, M.

G. Kanatzidis, Nat. Commun. 7, 12167 (2016).

${ }^{47}$ S. Wang, Y. Sun, J. Yang, B. Duan, L. Wu, W. Zhang, J. Yang, Energy Environ. Sci. 9, 3436 (2016); P. Ying, X. Li, Y. Wang, J. Yang, C. Fu, W. Zhang, X. Zhao, T. Zhu, Adv. Funct. Mater. 27, 1604145 (2017).

${ }^{48}$ Y. Tian, G. B. Osterhoudt, S. Jia, R. J. Cava, and K. S. Burch, Appl. Phys. Lett. 108, 041911 (2016).

${ }^{49}$ O. Hellman and D.A. Broido, Phys. Rev. B 90, 134309 (2014). 
${ }^{50}$ D. H. Kim, C. Kim, S. H. Heo, and H. Kim, Acta Mater. 59, 405 (2011).

${ }^{51}$ H. -J. Shang, F.-Z. Ding, Y. Deng, H. Zhang, Z. -B. Dong, W.-J. Xu, D.-X. Huang, H. -W. Gu, and Z. -G. Chen, Nanoscale 10, 20189 (2018).

${ }^{52}$ G. S. Okram, AIP Advances 2, 012178 (2012).

${ }^{53}$ C. S. Lue, C. N. Kuo, J. Y. Huang, H. L. Hsieh, H. Y. Liao, B. Ramachandran, and Y. K. Kuo, J. Phys. D: Appl. Phys. 46, 315303 (2013).

${ }^{54}$ C. B. Vining, W. Laskow, J. O. Hanson, R. R. Vanderbeck, and P. D. Gorsuch, J. Appl. Phys. 69, 4333 (1991).

${ }^{55}$ K. Biswas, J. He, Q. Zhang, G. Wang, C. Uher, V. P. Dravid and M. G. Kanatzidis, Nat. Chem. 3, 160 (2011).

${ }^{56}$ M. P. Das and F. Green, Adv. Nat. Sci- Nanosci. 8, 023001 (2017).

${ }^{57}$ V. L. Bonch-Bruevich and S. G. Kalashnikov, Physics of Semiconductors (VEB, Berlin, 1982).

${ }^{58}$ B. M. Askerov, Electron Transport Phenomena in Semiconductors (Nauka, Moscow, 1985).

${ }^{59}$ Q. Jin, S. Jiang, Y. Zhao, D. Wang, J. Qiu, D. -M. Tang, J. Tan, D. -M. Sun. P. -X. Hou, X.

Q. Chen, K. Tai, N. Gao, C. Liu, H. -M. Cheng, and X. Jiang, Nat. Mater.18, 62 (2019). 


\section{$\underline{\text { Figure Captions }}$}

FIG. 1. (a) Grain size and (b) strain of $\mathrm{Bi}_{2} \mathrm{Te}_{3}+x$ wt $\%$ graphite $(\mathrm{x}=0,0.5$, and 1.0) composites for three typical lattice planes after Rietveld refinement at room temperature. Estimated errors in the grain size and lattice strain are included. Errors in lattice strain $(\sim 1 \%)$ are within the size of data points.

FIG. 2. Room temperature Raman spectra of $\mathrm{Bi}_{2} \mathrm{Te}_{3}+\mathrm{x}$ wt $\%$ graphite $(\mathrm{x}=0,0.5$, and 1.0) nanocomposites. The peak marked with asterisk $(*)$ is attributed to the overtone modes of nanostructured $\mathrm{Bi}_{2} \mathrm{Te}_{3}$.

FIG. 3. Temperature dependence of (a) thermal conductivity ( $\kappa$ ) and (b) lattice part of thermal conductivity $\left(\kappa_{L}\right)$ (c) electronic part of thermal conductivity $\left(\kappa_{e}\right)$ for different weight percentage (x) of graphite in $\mathrm{Bi}_{2} \mathrm{Te}_{3} /$ graphite nanocomposites. The typical errors in $\kappa_{e}$ value are within the size of the data points.

FIG. 4. Phonon density of states (PDOS) for pristine $\mathrm{Bi}_{2} \mathrm{Te}_{3}, \mathrm{Bi}_{2} \mathrm{Te}_{3}+1.0 \mathrm{wt} \%$ graphite and pure graphite. The low energy spectra have been integrated from 3 to $5 \AA^{-1}$. The pure graphite has been scaled by 0.005 based on the relative intensity of the graphite Bragg peaks present in the composite sample. (Inset) Debye level calculated from the specific PDOS measurement.

FIG. 5. Thermal variation of Seebeck Coefficient $(S)$ for different weight percentage (x) of graphite in $\mathrm{Bi}_{2} \mathrm{Te}_{3} /$ graphite nanocomposites.

FIG. 6. Temperature dependent Resistivity $(\rho)$ for different weight percentage (x) of graphite in $\mathrm{Bi}_{2} \mathrm{Te}_{3} /$ graphite nanocomposites.

FIG. 7. Temperature dependent Carrier concentration $\left(n_{H}\right)$ for different weight percentage $(\mathrm{x})$ of Graphite in $\mathrm{Bi}_{2} \mathrm{Te}_{3} /$ graphite nanocomposites. The typical errors in $n_{H}$ value are within the size of the data points.

FIG. 8. Dependence of (a) Seebeck coefficient, $S$; and (b) resistivity, $\rho$ on the position of Fermi level with respect to $\mathrm{E}_{0}$ at $300 \mathrm{~K}$ for single band $1 \mathrm{D}$ and $3 \mathrm{D}$ electron transport.

FIG. 9: Temperature dependencies of (a) Seebeck coefficient, $S$; (b) electrical resistivity, $\rho$; experimental (points), simulated (single 1D channel, double 1D channel and 3D transport model) and (c) electronic part of thermal conductivity, $\kappa_{e}$ experimental (points) and simulated (1D transport model) results of $\mathrm{Bi}_{2} \mathrm{Te}_{3}+1.0 \mathrm{wt} \%$ graphite nanocomposite sample. 
TABLE I. The best fit value of the parameters $A_{1}$ and $A_{2}$; as obtained from fitting thermopower data with equation: $S=S_{0}+A_{1} T+A_{2} T^{3}$

\begin{tabular}{ccc}
\hline \hline Sample $(\mathrm{x})$ & $\left|\mathrm{A}_{1}\right|\left(\mu \mathrm{VK}^{-2}\right)$ & $\mathrm{A}_{2}\left(\mu \mathrm{VK}^{-4}\right)$ \\
\hline 0 & $0.278 \pm 0.0018$ & $3.8 \times 10^{-6} \pm 7.3 \times 10^{-7}$ \\
0.5 & $0.345 \pm 0.0257$ & $4.4 \times 10^{-6} \pm 2.5 \times 10^{-7}$ \\
1.0 & $0.358 \pm 0.0089$ & $4.6 \times 10^{-6} \pm 9.2 \times 10^{-7}$ \\
\hline \hline
\end{tabular}

TABLE II. Electron parameters calculated using experimentally measured Hall concentration and electric conductivity data for $0.1 \mathrm{~m} 0$ effective mass for $\mathrm{Bi}_{2} \mathrm{Te}_{3}+\mathrm{x} w t \%$ graphite samples.

\begin{tabular}{cccccc}
\hline $\begin{array}{c}\text { Graphite content } \\
(\mathrm{wt} \%)\end{array}$ & $\begin{array}{c}\mathrm{n}_{\mathrm{H}} \\
\left(10^{18} \mathrm{~cm}^{-3}\right)\end{array}$ & $\begin{array}{c}\mu \\
\left(\mathrm{cm}^{2} / \mathrm{V}-\mathrm{s}\right)\end{array}$ & $\begin{array}{c}\mathrm{EF}_{\mathrm{F}} \\
(\mathrm{meV})\end{array}$ & $\begin{array}{c}l \\
(\mathrm{~nm})\end{array}$ & $\begin{array}{c}\lambda \\
(\mathrm{nm})\end{array}$ \\
\hline 0 & 0.2 & 39.0 & 4.5 & 2.60 & 65 \\
0.5 & 5.0 & 4.5 & 39.0 & 0.85 & 22 \\
1.0 & 1.5 & 23.0 & 17.0 & 3.00 & 32 \\
\hline \hline
\end{tabular}



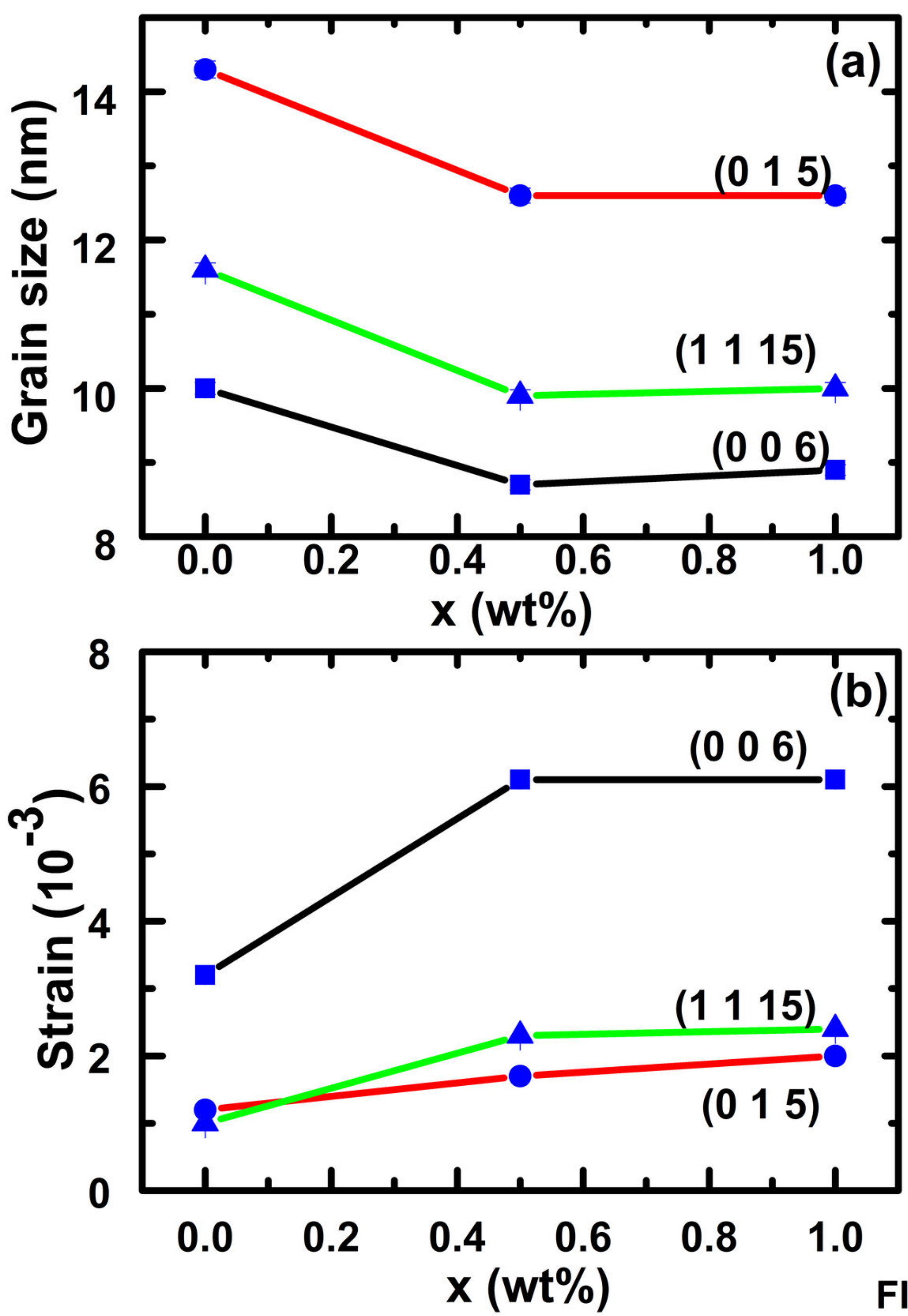

FIG. 1 


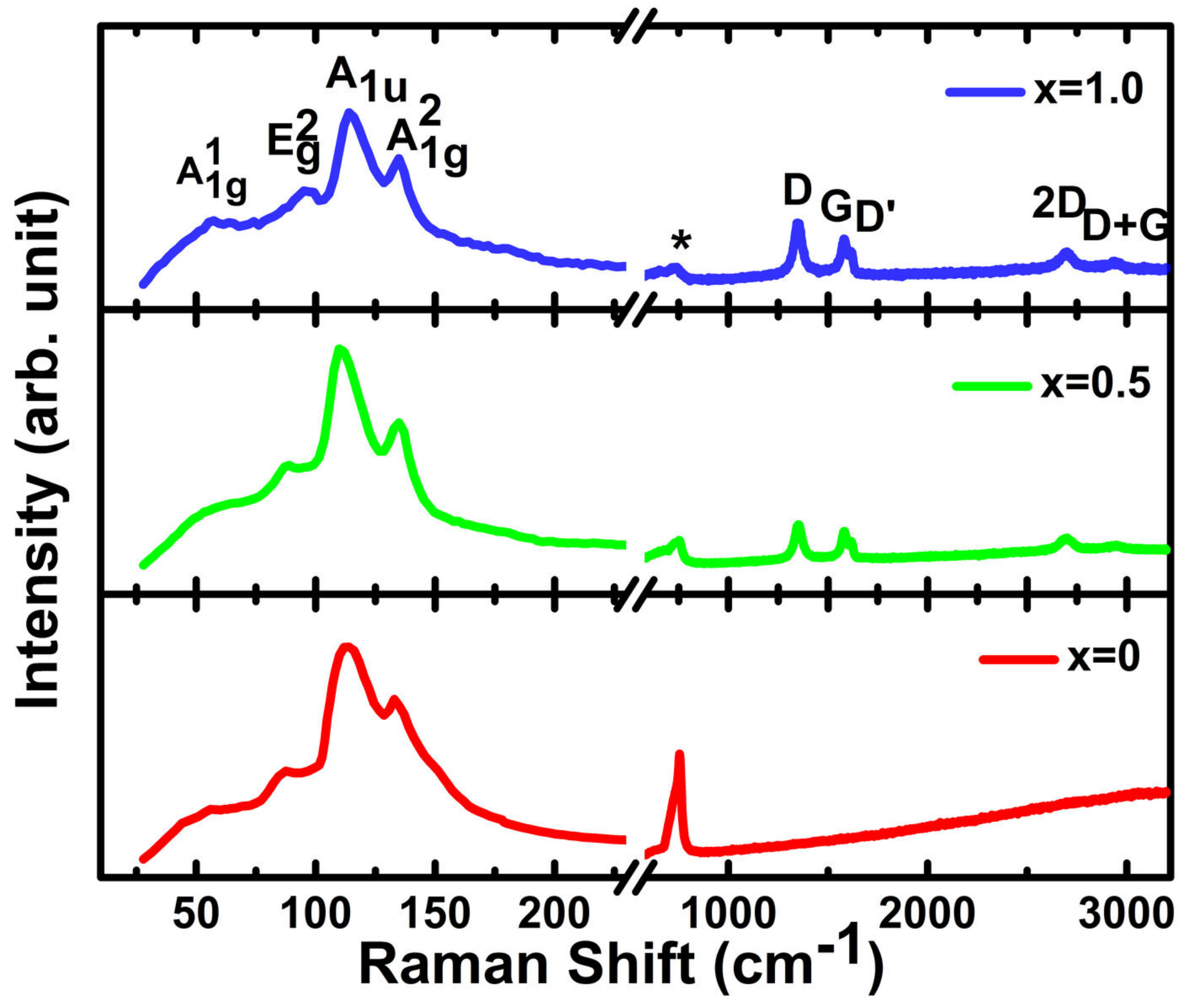

FIG. 2 


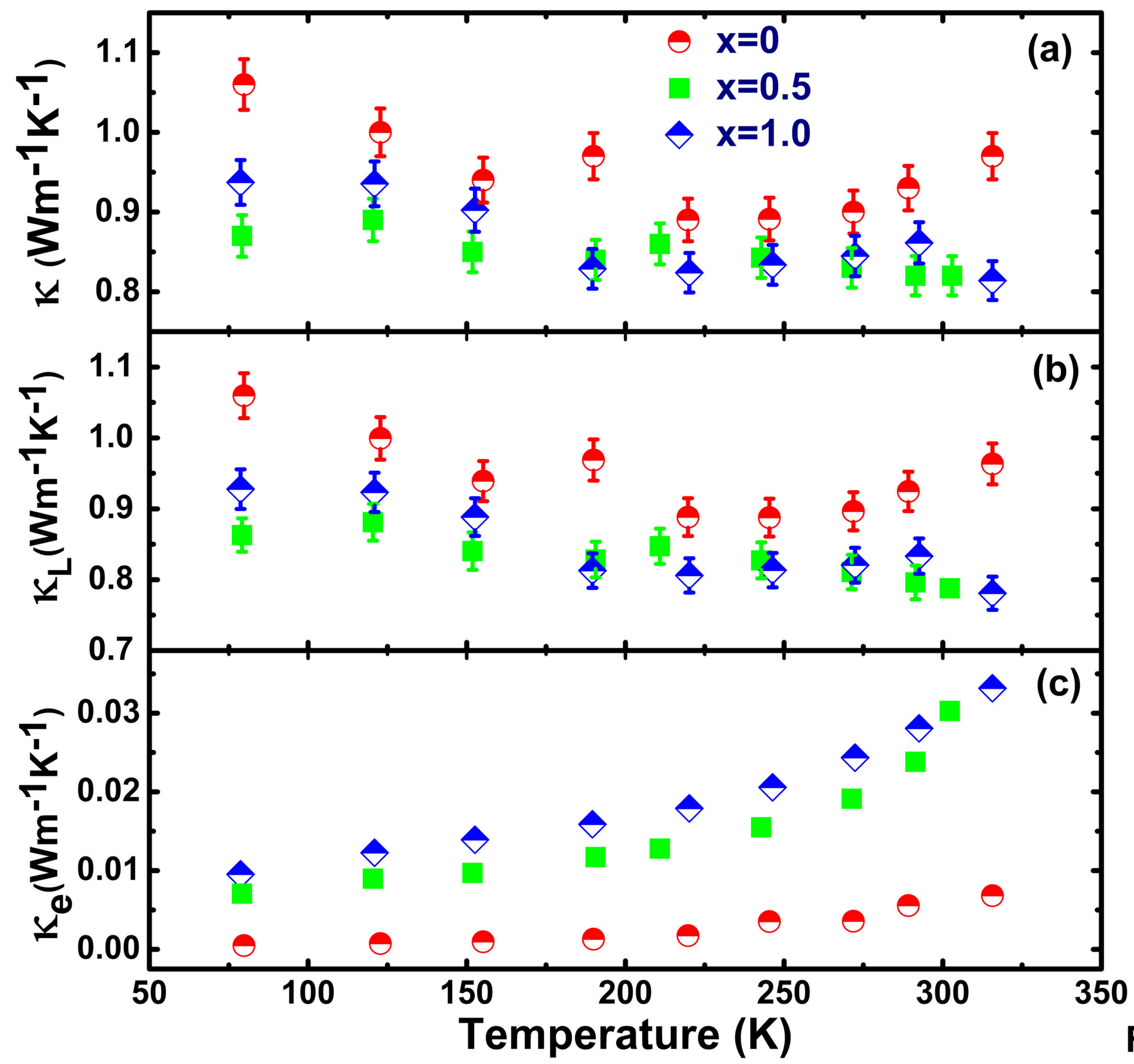

FIG. 3 


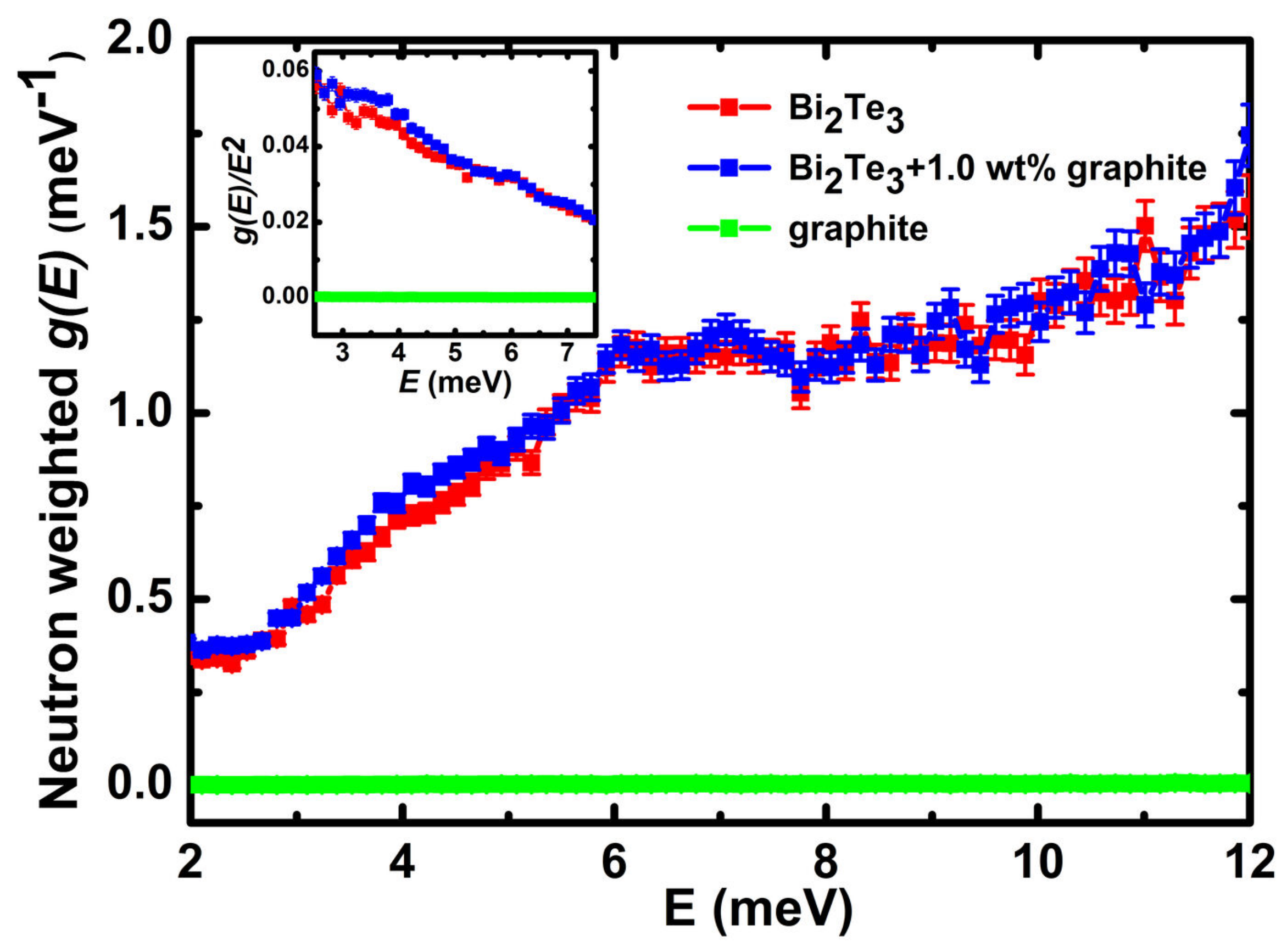

FIG. 4 


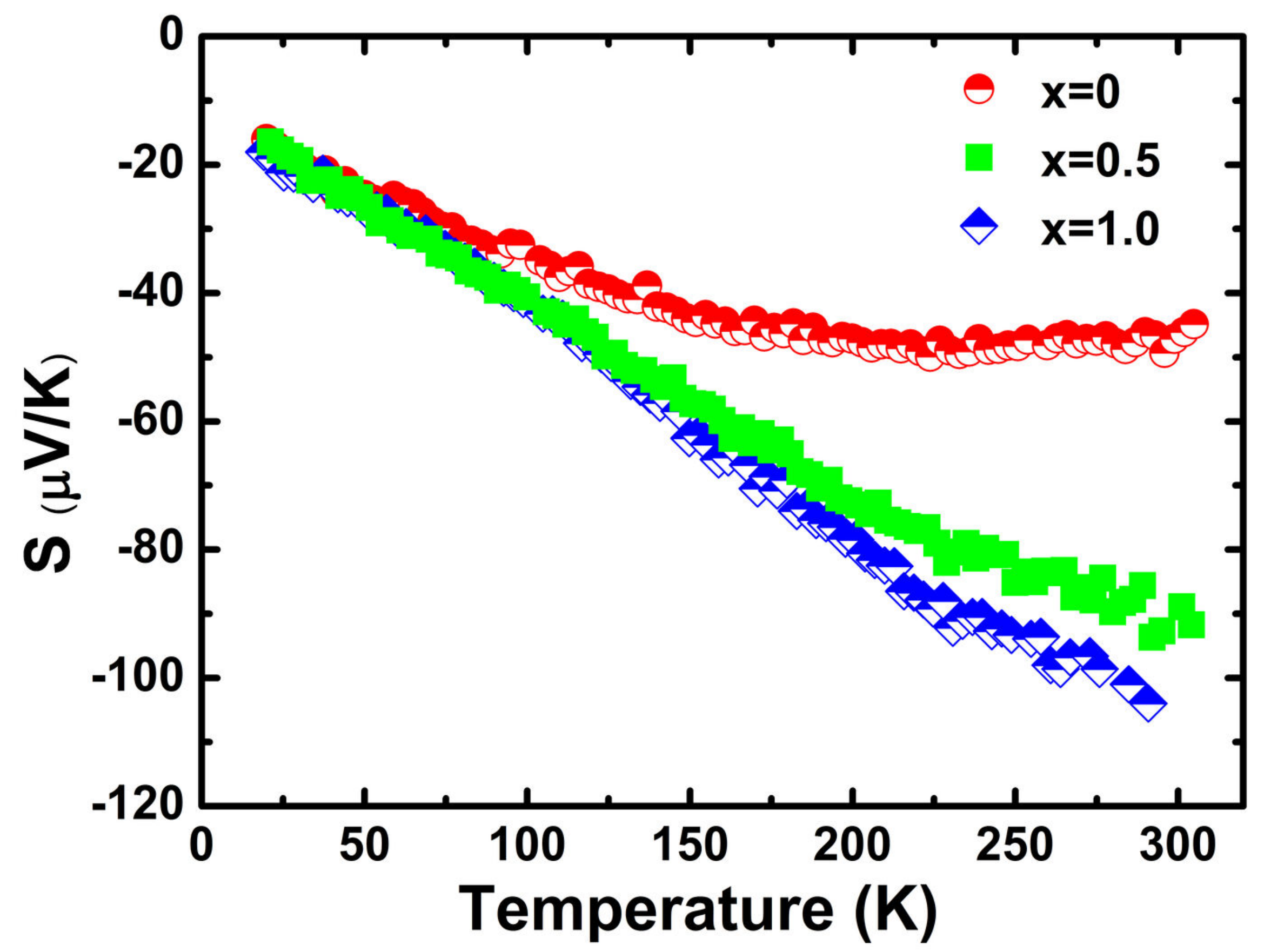

FIG. 5 


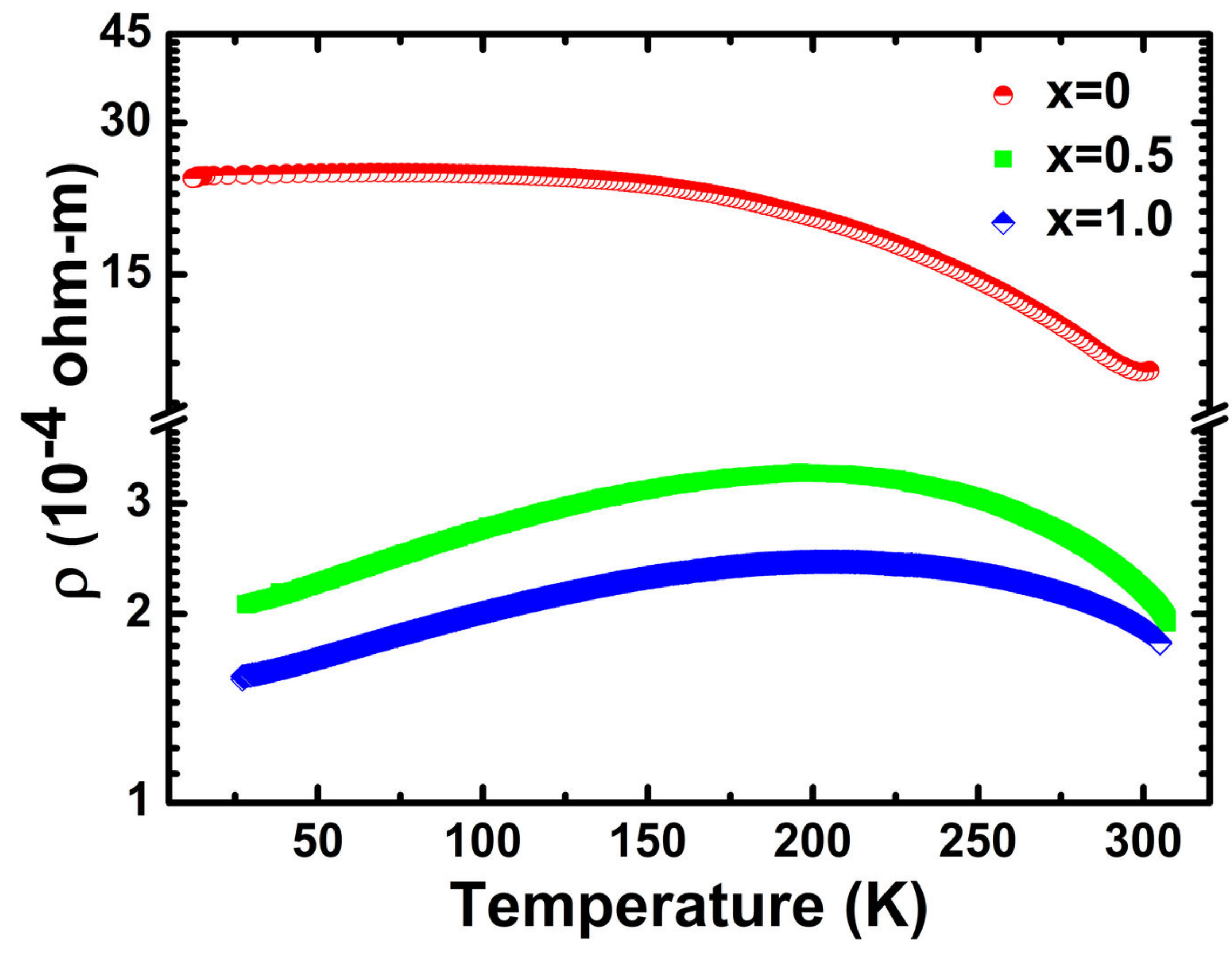

FIG. 6 


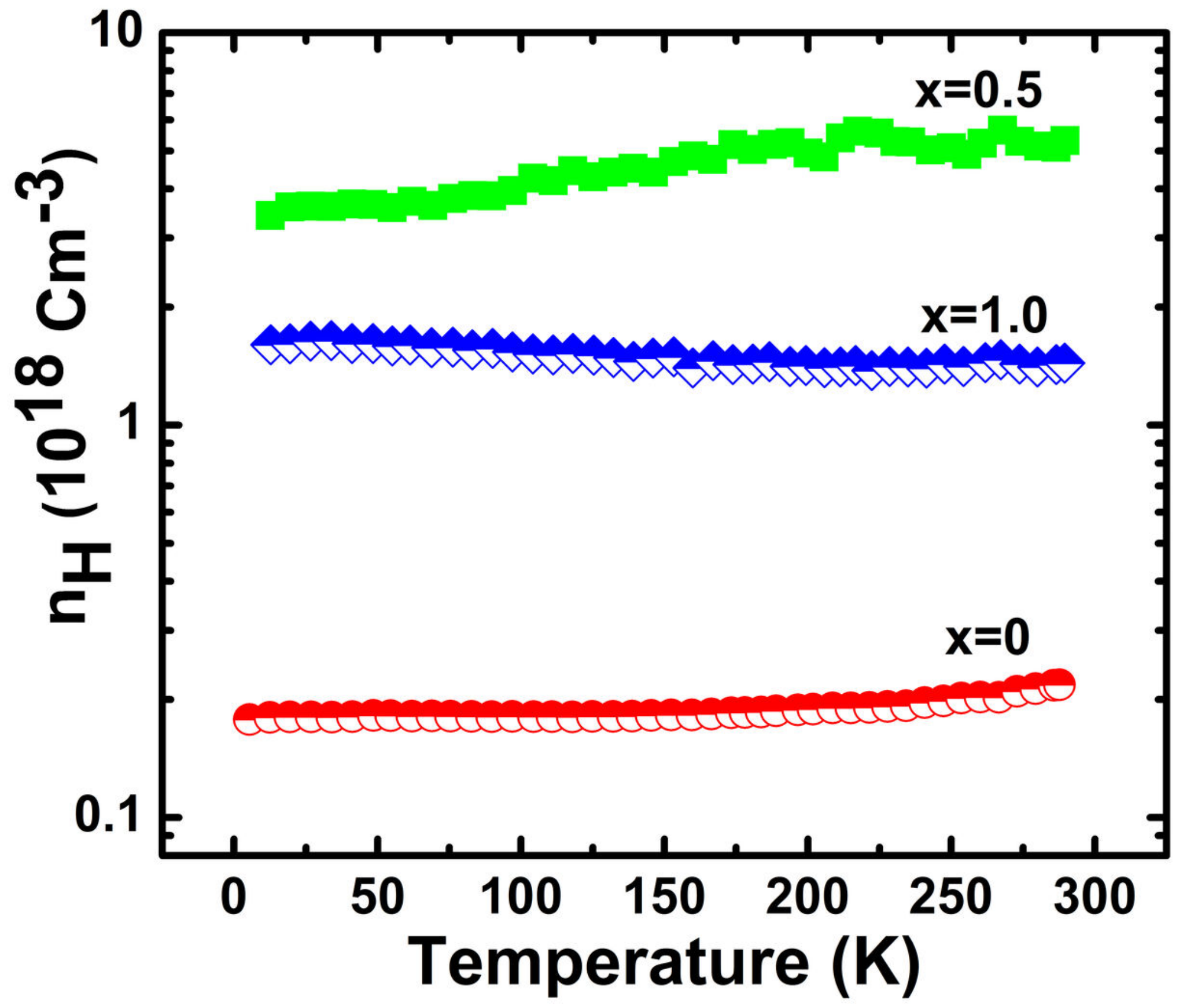

FIG. 7 


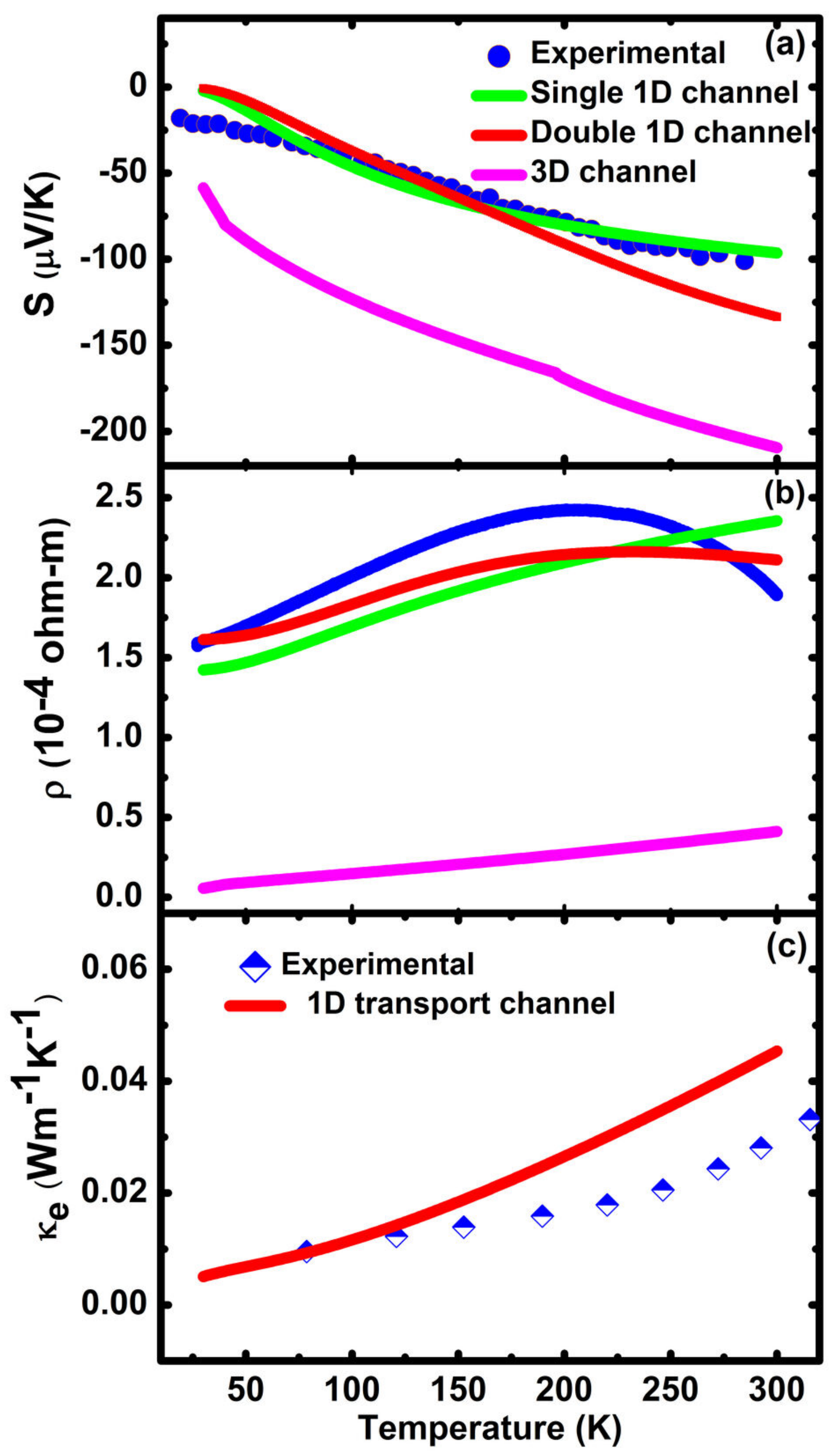

FIG. 9 